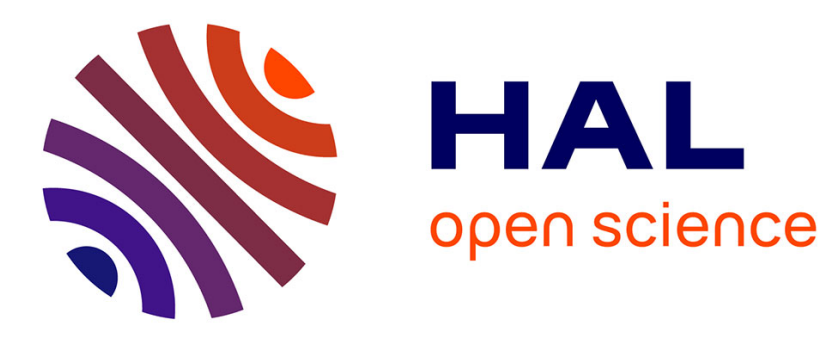

\title{
Absorption cross-sections of Ozone in the ultraviolet and visible spectral regions - Status report 2015
}

Johannes Orphal, Johannes Staehelin, Johanna Tamminen, Geir Braathen, Marie-Renée de Backer, Alkiviadis Bais, Dimitris Balis, Alain Barbe, Pawan K. Bhartia, Manfred Birk, et al.

\section{To cite this version:}

Johannes Orphal, Johannes Staehelin, Johanna Tamminen, Geir Braathen, Marie-Renée de Backer, et al.. Absorption cross-sections of Ozone in the ultraviolet and visible spectral regions - Status report 2015. Journal of Molecular Spectroscopy, 2016, 327, pp.105-121. 10.1016/j.jms.2016.07.007 . insu-01349533

\section{HAL Id: insu-01349533 \\ https://hal-insu.archives-ouvertes.fr/insu-01349533}

Submitted on 15 Nov 2019

HAL is a multi-disciplinary open access archive for the deposit and dissemination of scientific research documents, whether they are published or not. The documents may come from teaching and research institutions in France or abroad, or from public or private research centers.
L'archive ouverte pluridisciplinaire HAL, est destinée au dépôt et à la diffusion de documents scientifiques de niveau recherche, publiés ou non, émanant des établissements d'enseignement et de recherche français ou étrangers, des laboratoires publics ou privés. 


\section{Absorption cross-sections of ozone in the ultraviolet and visible spectral regions - Status report 2015}

Johannes Orphal $^{\mathrm{a}, *}$, Johannes Staehelin ${ }^{\mathrm{b}}$, Johanna Tamminen ${ }^{\mathrm{c}}$, Geir Braathen ${ }^{\mathrm{d}}$, Marie-Renée De Backer ${ }^{\mathrm{e}}$, Alkiviadis Bais ${ }^{\mathrm{f}}$, Dimitris Balis ${ }^{\mathrm{f}}$, Alain Barbe ${ }^{\mathrm{e}}$, Pawan K. Bhartia ${ }^{\mathrm{g}}$, Manfred Birk ${ }^{\mathrm{h}}$, James W. Burkholder ${ }^{\mathrm{i}}$, Kelly V. Chance ${ }^{\mathrm{j}}$, Thomas von Clarmann ${ }^{\mathrm{a}}$, Anthony Cox ${ }^{\mathrm{k}}$, Doug Degenstein ${ }^{1}$, Robert Evans ${ }^{\mathrm{i}}$, Jean-Marie Flaud ${ }^{\mathrm{m}}$, David Flittner $^{n}$, Sophie Godin-Beekmann ${ }^{o}$, Viktor Gorshelev ${ }^{\mathrm{p}}$, Aline Gratien ${ }^{\mathrm{m}}$, Edward Hare ${ }^{\mathrm{q}}$, Christof Janssen ${ }^{\mathrm{r}}$, Erkki Kyrölä ${ }^{\mathrm{c}}$, Thomas McElroy ${ }^{\mathrm{s}}$, Richard McPeters ${ }^{\mathrm{g}}$, Maud Pastel ${ }^{\mathrm{o}}$, Michael Petersen ${ }^{\mathrm{t}}$, Irina Petropavlovskikh ${ }^{\mathrm{i}}$, Benedicte Picquet-Varrault ${ }^{\mathrm{m}}$, Michael Pitts ${ }^{\mathrm{n}}$, Gordon Labow ${ }^{\mathrm{g}}$, Maud Rotger-Languereau ${ }^{\mathrm{e}}$, Thierry Leblanc ${ }^{\mathrm{u}}$, Christophe Lerot ${ }^{\mathrm{v}}$, Xiong Liu ${ }^{\mathrm{j}}$, Philippe Moussay ${ }^{\mathrm{t}}$, Alberto Redondas ${ }^{\mathrm{w}}$, Michel Van Roozendael ${ }^{\mathrm{v}}$, Stanley P. Sander ${ }^{\mathrm{u}}$, Matthias Schneider ${ }^{\mathrm{a}}$, Anna Serdyuchenko ${ }^{\mathrm{p}}$, Pepijn Veefkind ${ }^{\mathrm{x}}$, Joële Viallon ${ }^{\mathrm{t}}$, Camille Viatte ${ }^{\mathrm{y}}$, Georg Wagner ${ }^{\mathrm{h}}$, Mark Weber ${ }^{\mathrm{p}}$, Robert I. Wielgosz ${ }^{\mathrm{t}}$, Claus Zehner ${ }^{\mathrm{z}}$

a Institute for Meteorology and Climate Research (KIT), Karlsruhe Institute of Technology (KIT), Karlsruhe, Germany

${ }^{\mathrm{b}}$ Swiss Federal Institute of Technology (ETH), Zurich, Switzerland

${ }^{c}$ Finnish Meteorological Institute (FMI), Helsinki, Finland

${ }^{\mathrm{d}}$ World Meteorological Organization (WMO), Geneva, Switzerland

e GSMA, CNRS and University of Reims, Reims, France

${ }^{\mathrm{f}}$ Aristotele University of Thessaloniki, Thessaloniki, Greece

g Goddard Space Flight Center (GSFC), NASA, Greenbelt, MD, USA

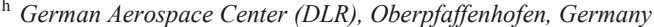

i Cooperative Institute for Research in Environmental Sciences (CIRES), University of Colorado, Boulder, CO, USA

${ }^{\mathrm{j}}$ Harvard-Smithsonian Center for Astrophysics, Cambridge, MA, USA

${ }^{\mathrm{k}}$ University of Cambridge, Cambridge, UK

${ }^{1}$ University of Saskatchewan, Saskatoon, Canada

$\mathrm{m}$ LISA, CNRS and University of Paris-Est, Creteil, France

${ }^{\mathrm{n}}$ Langley Research Center, NASA, Hampton, VA, USA

o LATMOS, CNRS and University of Versailles-St. Quentin (UVSQ), Paris, France

${ }^{\mathrm{p}}$ University of Bremen, Bremen, Germany

${ }^{\mathrm{q}}$ Environment Canada, Toronto, Canada

${ }^{\mathrm{r}}$ LERMA, CNRS and University of Paris, Paris, France

s University of Toronto, Toronto, Canada

${ }^{\mathrm{t}}$ International Bureau of Weights and Measures (BIPM), Sevres, France

u Jet Propulsion Laboratory (JPL), NASA, Pasadena, USA

v Belgian Institute for Space Aeronomy (BIRA-IASB), Brussels, Belgium

${ }^{w}$ State Meteorological Agency (AEMET), Izana, Spain

${ }^{\mathrm{x}}$ KNMI, De Bilt, The Netherlands

${ }^{y}$ California Institute of Technology, Pasadena, CA, USA

${ }^{\mathrm{z}}$ ESRIN, European Space Agency (ESA), Frascati, Italy

\section{A R T I C L E IN F O}

Article history:

Received 20 January 2016

Received in revised form 27 June 2016 Accepted 20 July 2016

Available online $\mathrm{xxx}$

Keywords:

Ozone

Absorption

Cross sections

Atmosphere

Remote sensing

Reference data

* Corresponding author.

Email address: orphal@kit.edu (J. Orphal)
A B S T R A C T

The activity "Absorption Cross-Sections of Ozone" (ACSO) started in 2008 as a joint initiative of the International Ozone Commission (IO3C), the World Meteorological Organization (WMO) and the IGACO ("Integrated Global Atmospheric Chemistry Observations") $\mathrm{O}_{3} / \mathrm{UV}$ subgroup to study, evaluate, and recommend the most suitable ozone absorption cross-section laboratory data to be used in atmospheric ozone measurements. The evaluation was basically restricted to ozone absorption cross-sections in the UV range with particular focus on the Huggins band. Up until now, the data of Bass and Paur published in 1985 (BP, 1985) are still officially recommended for such measurements. During the last decade it became obvious that BP (1985) cross-section data have deficits for use in advanced space-borne ozone measurements. At the same time, it was recognized that the origin of systematic differences in ground-based measurements of ozone required further investigation, in particular whether the BP (1985) cross-section data might contribute to these differences. 
In ACSO, different sets of laboratory ozone absorption cross-section data (including their dependence on temperature) of the group of Reims (France) (Brion et al., 1993, 1998, 1992, 1995, abbreviated as BDM, 1995) and those of Serdyuchenko et al. (2014), and Gorshelev et al. (2014), (abbreviated as SER, 2014) were examined for use in atmospheric ozone measurements in the Huggins band.

In conclusion, $\mathrm{ACSO}$ recommends:

(a) The spectroscopic data of BP (1985) should no longer be used for retrieval of atmospheric ozone measurements.

(b) For retrieval of ground-based instruments of total ozone and ozone profile measurements by the Umkehr method performed by Brewer and Dobson instruments data of SER (2014) are recommended to be used. When SER (2014) is used, the difference between total ozone measurements of Brewer and Dobson instruments are very small and the difference between Dobson measurements at $\mathrm{AD}$ and $\mathrm{CD}$ wavelength pairs are diminished.

(c) For ground-based Light Detection and Ranging (LIDAR) measurements the use of BDM (1995) or SER (2014) is recommended.

(d) For satellite retrieval the presently widely used data of BDM (1995) should be used because SER (2014) seems less suitable for retrievals that use wavelengths close to $300 \mathrm{~nm}$ due to a deficiency in the signal-to-noise ratio in the SER (2014) dataset.

The work of ACSO also showed:

- The need to continue laboratory cross-section measurements of ozone of highest quality. The importance of careful characterization of the uncertainties of the laboratory measurements.

- The need to extend the scope of such studies to other wavelength ranges (particularly to cover not only the Huggins band but also the comparison with the mid-infrared region).

- The need for regular cooperation of experts in spectral laboratory measurements and specialists in atmospheric (ozone) measurements.

(C) 2016 Published by Elsevier Ltd.

\section{Introduction}

\subsection{The international ACSO initiative (2008-2015)}

This report presents the results of the "Absorption Cross-Sections of Ozone" (ACSO) activity, created in 2008 as a joint initiative of the International Ozone Commission (IO3C), the World Meteorological Organization (WMO), and the IGACO ("Integrated Global Atmospheric Chemistry Observations”) O3/UV Subgroup.

The official mandate of the ACSO initiative, chaired by Johannes Orphal (KIT, Karlsruhe, Germany), together with Johanna Tamminen (FMI, Helsinki, Finland), Johannes Staehelin (ETH Zurich, Switzerland) and Geir Braathen (WMO, Geneva, Switzerland) constituting the ACSO Steering Committee, was created with the task of producing a critical intercomparison of existing ozone absorption cross-sections and their impact on atmospheric ozone retrievals from the ground and satellites. If necessary, a new standard for reference ozone absorption cross-sections should be recommended, and its implementation for all atmospheric measurements of ozone would have to be initiated. Finally, a report with all the findings and recommendations of ACSO would need to be prepared.

The full ACSO group was established in 2008 with a large participation of leading experts from three different communities: (1) ground-based ozone measurements (e.g. Dobson, Brewer, Umkehr, LIDAR and Differential Optical Absorption Spectroscopy (DOAS) methods, including the Network for the Detection of Atmospheric Composition Change (NDACC) network), (2) satellite instruments for atmospheric ozone measurements (e.g. Total Ozone Mapping Spectrometer (TOMS), Solar Backscatter Ultraviolet Radiometer (SBUV), Stratospheric Aerosol and Gas Experiment (SAGE), Global Ozone Monitoring Experiment (GOME)/SCanning Imaging Absorption spectroMeter for Atmospheric Cartography (SCIAMACHY), Ozone Monitoring Instrument (OMI), etc.), and (3) the laboratory community where currently new reference data are being produced. The work was done in two phases. In the first phase, three dedicated workshops were held at WMO in 2009, 2010, and 2011 in which the set of temperature-dependent ultraviolet-visible absorption cross-sec- tions of ozone measured and published by a group of scientists from Reims (France) in the mid-1990s, usually referred to as BDM [1-4] was mostly considered to replace the presently recommended dataset from Bass and Paur [5,6]. In the second phase in 2013, the novel absorption cross-sections of ozone published by Gorshelev et al. [7], Serdyuchenko et al. [8] became available and an additional workshop was arranged at WMO in 2013. The Final Report (ACSO Status Report 2015) was prepared in 2014-2015 and officially released as "WMO - GAW Report No. 218".

\subsection{Scientific background}

Atmospheric ozone is presently measured from the ground and space by a large number of methods (see e.g. Ref. [9] and references therein) most of them making use of interaction of (solar) radiation with ozone including many different wavelength ranges. Absorption cross-sections of ozone are an essential parameter for the determination of atmospheric ozone concentrations from ultraviolet and visible spectra. While satellite measurements provide global coverage, measurements from the ground are essential to validate satellite ozone measurements and ensure their long-term stability and, therefore, it is desirable to use the same laboratory spectroscopic data for ground-based and satellite measurements in order to minimize error sources for the comparison. Since the discovery of the strong absorption band of ozone in the ultraviolet by Hartley in 1880, and the following measurements of Chappuis and Huggins, accurate knowledge of the absorption cross-sections of ozone and its dependence on temperature has always been the subject of laboratory investigations. In particular, every time that a novel spectroscopic technique has been developed, new requirements on the accuracy and precision of the ozone absorption cross-sections have arisen. Therefore, several times, new and improved values of the ozone absorption cross-sections in the $250-800 \mathrm{~nm}$ spectral range have been proposed over the last 100 years, and many of them in the last three decades.

For time series of atmospheric ozone concentrations and column amounts, the consistency of new absorption cross-sections with previous values is essential. An accuracy of better than a percent is re- 
quired to limit the impact of systematic uncertainties on the determination of ozone trends. Also, the consistency of the absorption cross-sections at different temperatures is very important, due to the variable vertical distributions of ozone and temperature in the atmosphere. The detailed study of these effects and their impact on atmospheric ozone retrievals was an important task for ACSO. A detailed overview and critical review of laboratory measurements of ozone absorption cross-sections prior to $2001[10,11]$ is available on the ACSO homepage (http://igaco-o3.fmi.fi/ACSO/). However, this report did not deal with cross-sections issues related to atmospheric measurements. Therefore, studying the impact of using different reference ozone absorption cross-sections for atmospheric remote-sensing was an essential element of ACSO. Finally, several recent laboratory measurements of ozone absorption cross-sections needed to be evaluated in the context of ACSO.

Most of all, the series of four ACSO workshops at WMO in Geneva (2009, 2010, 2011 and 2013) have brought together experts from different communities. The presentations and discussions were very interesting and useful, and recommendations of reference data of ozone absorption cross-sections to be used in atmospheric retrievals were made on the basis of a large general consensus. From the many contributions to ACSO and discussions thereof, needs for future research have been as well identified and formulated.

2. Laboratory measurements and evaluations of ozone absorption cross-sections in the ultraviolet-visible and infrared (2009-2011)

\subsection{Introduction}

Accurate quantitative laboratory measurements of ozone are difficult. $\mathrm{O}_{3}$ must be produced in the laboratory and cannot be purchased in high-purity samples like other gases. Ozone samples may contain impurities such as $\mathrm{O}_{2}, \mathrm{H}_{2} \mathrm{O}$, nitrogen oxides or $\mathrm{CO}_{2}$, which are not always easy to detect with the same laboratory techniques. For example, $\mathrm{O}_{2}$ does not absorb in the mid-infrared where the strongest ozone bands are located, while small amounts of $\mathrm{CO}_{2}$ or $\mathrm{H}_{2} \mathrm{O}$ cannot be seen in the ultraviolet or visible regions. Also, pure $\mathrm{O}_{3}$ samples will decompose slowly in an absorption cell. All these difficulties need to be solved in order to provide accurate ozone absorption cross-sections or individual line intensities in the mid-infrared.

Furthermore, $\mathrm{O}_{3}$ absorption cross-sections are required over a large spectral range: in the ultraviolet-visible region, ozone absorbs at all wavelengths between 200 and $1100 \mathrm{~nm}$ covering a very large dynamic range: the highest absorption of about $10^{-17} \mathrm{~cm}^{2}$ molecule ${ }^{-1}$ is observed at the peak of the Hartley band around $250 \mathrm{~nm}$, while the absorption cross-sections of ozone around $385 \mathrm{~nm}$ (between the Huggins and Chappuis bands) are less than $5 \times 10^{-23} \mathrm{~cm}^{2}$ molecule ${ }^{-1}$. In the mid-infrared, the strongest lines of the $\nu_{1}$ and $\nu_{3}$ bands around $10 \mathrm{~mm}$ $\left(1000 \mathrm{~cm}^{-1}\right)$ have similar strong absorption as the Hartley band, but it seems impossible to measure both regions simultaneously with the same spectrometer. Again, this makes quantitative measurements of $\mathrm{O}_{3}$ in the laboratory very challenging: the experimental set-up must cover a large spectral range and a huge dynamic range. If all the ultraviolet-visible region needs to be covered, more than 7 orders of magnitude are required.

Finally, the requirements for laboratory measurements of ozone absorption cross-sections and infrared line intensities are very high, due to the increasing need for highly accurate measurements of atmospheric ozone. For atmospheric retrievals the absolute accuracy of the absorption cross-sections (or infrared line intensities) should be better than $1 \%$, data at high spectral resolution are needed (typically $0.01 \mathrm{~nm}$ in the ultraviolet-visible), the spectral (wavelength) calibra- tion must be very accurate, too (typically at least $0.01 \mathrm{~nm}$ ), and the experimental $\mathrm{O}_{3}$ absorption cross-sections must be available at all atmospheric temperatures (i.e. in the range $180-300 \mathrm{~K}$ and measured at least at 5 different temperatures in order to allow interpolation for intermediate values). Of course, the data should contain low noise (less than $1 \%$ ) and little baseline (background) variations.

The laboratory data of ozone that are available today do not fulfil all these requirements. Each dataset has some limitations (like the spectral or temperature range, or spectral resolution or calibration accuracy), which are not always easy to identify.

In the ACSO activities, the team discussed existing quantitative spectroscopic laboratory measurements of ozone, in order to support the ACSO effort to provide a recommendation for ozone absorption cross-sections. In parallel, new laboratory measurements were prepared and pursued, and the new results were presented at the four ACSO meetings in 2009, 2010, 2011, and 2013.

This chapter briefly describes the main results related to this part of the ACSO activity.

\subsection{New laboratory measurements and main results during ACSO}

At the ACSO meetings the following papers on laboratory measurements were presented for discussion by:

- Viallon et al. from BIPM in Paris-Sèvres (France) concerning requirements for new laboratory measurements of ozone absorption cross-sections in the ultraviolet and new laser-based measurements of ozone concentration in the Hartley Band and corresponding absorption cross-section [12-14].

- Janssen et al. from LPMAA and LERMA in Paris (France) concerning new measurements of ozone absorption cross-sections at $253.65 \mathrm{~nm}$ (mercury line) and simultaneous ultraviolet-infrared (UV-IR) measurements [16,17].

- Orphal et al. from LISA in Paris-Créteil (France) and KIT Karlsruhe (Germany) concerning available laboratory measurements of ozone absorption cross-sections including UV-IR intercomparisons in the laboratory and in atmospheric measurements [18-29].

- Burkholder et al. from NOAA Boulder (USA) concerning new laboratory measurements of ozone absorption cross-sections in the ultraviolet using a laser spectrometer [30,31].

- Serdyuchenko et al. from University of Bremen (Germany) on new broadband Ultraviolet-Visible Near Infrared Spectroscopy (UV-vis-NIR) measurements using Echelle and Fourier-Transform spectrometers as part of the ESA HARMONICS project "Harmonization of GOME, SCIAMACHY and GOME-2 ozone and $\mathrm{NO}_{2}$ cross-sections" [7,8,32-34].

- Barbe et al. from GSMA in Reims (France) with an overview of past, current and future laboratory measurements [1-4,22,23,35].

It is important to note that all new measurements show very good consistency with and similar quality than the data by Brion et al. [1-4], see e.g. Fig. 1, although their absolute values in the peak of the Hartley band show some discrepancy with respect to the recommended value by Hearn in 1961 [36], see in particular Petersen et al. [13]. This issue obviously requires further experimental investigations.

Furthermore, some measurements were made outside the ACSO team, using a new sensitive laboratory technique ("Incoherent Broad-Band Cavity-Enhanced Absorption Spectroscopy", IBB-CEAS) in the absorption minimum between the Huggins and Chappuis bands [37,38], see Fig. 2. These measurements do confirm the high quality of the data by Brion et al. [1-4], while reducing their uncertainty 



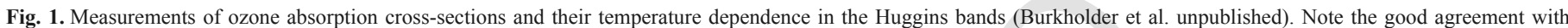
previous measurements of Burrows et al. [43] and BDM (1998).

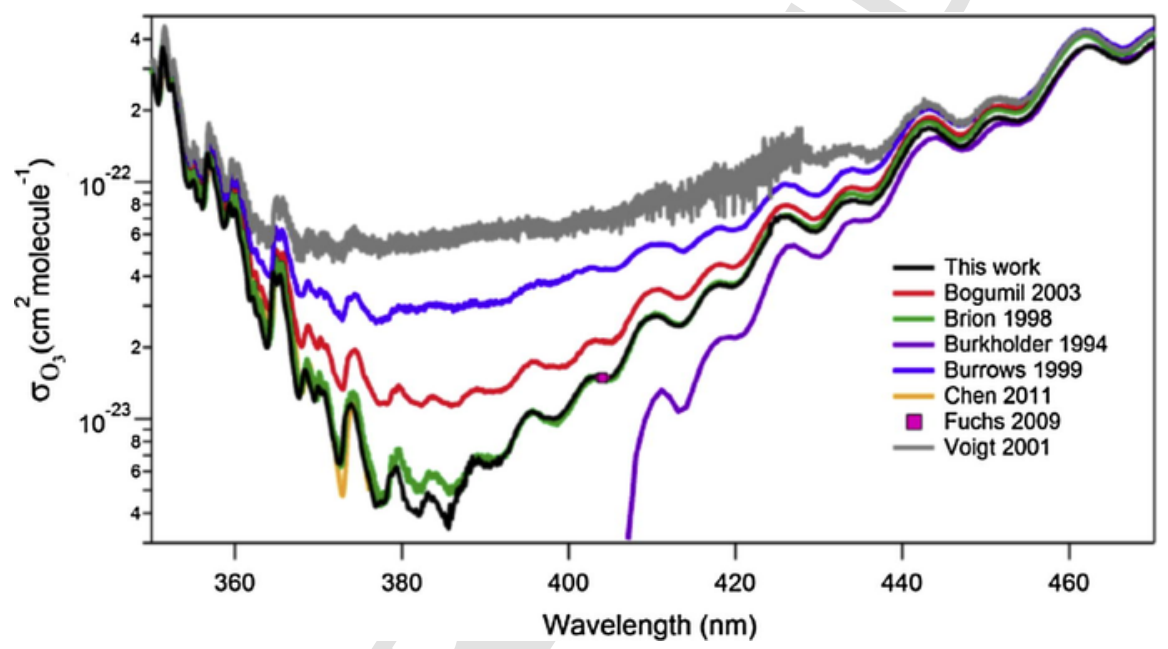

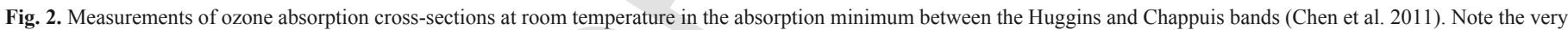
good agreement with the previous measurements of Brion et al. [4]

this region. However, the new measurements are available at room temperature only.

The new measurements of ultraviolet-visible and near-infrared ozone absorption cross-sections at eleven different temperatures (193-273 K) made at the Institute of Environmental Physics (IUP), University of Bremen [7,8] are a very interesting set of data (see e.g. Fig. 3). They have become available to the science community rather recently, so that the ACSO activities were extended for another year to enable some investigations on their use in atmospheric measurements.

The IUP Bremen group also revised broadband ozone absorption cross-section data that were obtained from laboratory measurements using the satellite flight spectrometer (FM) prior to their launch. The Bogumil et al. (2003) data [20], also known as SCIAMACHY FM, were revised (Version 4) to resolve the systematic biases seen in their use with SCIAMACHY retrievals in the Huggins band [34]. GOME-2 FM3 (now flying on the Meteorological Operational satellite pro- gramme "Metop-A") ozone cross-section data have been published and released as well [33] and are an update of Gür [32]. The so-called FM data, that also include the data from GOME FM [18], are mostly relative cross-sections (scaled to literature data, mainly from Refs. [1-6] and have rather low spectral resolution $(\sim 0.2 \mathrm{~nm})$ compared to Refs. [1-8].

An overview of the status of infrared line intensities and related laboratory measurements have been published by Smith et al. [39]. Clearly, there is urgent need for new laboratory measurements also in the mid-infrared, if possible together with simultaneous measurement of the ozone absorption at $253.65 \mathrm{~nm}$.

Highly accurate and precise measurements of the mercury line absorption of ozone $(253.65 \mathrm{~nm})$ are also needed [17], see Fig. 4. Very recently, Viallon et al. [14] reported updated room temperature measurements of the mercury line $(253.65 \mathrm{~nm})$. Their value lies about $1.8 \%$ below the Hearn value [36] that has been frequently used for absolute scaling of broadband ozone absorption cross-sections. 


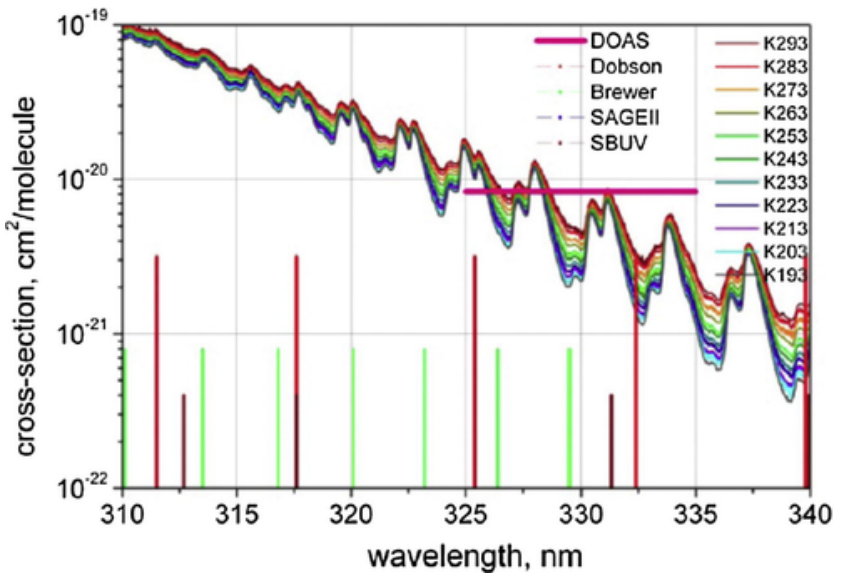

Fig. 3. New measurements of ozone absorption cross-sections at different temperatures (193-293 K) temperature in the Huggins bands [7,8] including wavelengths indicated as used for different instruments.

Very recent results from Janssen et al. [17] are within error bars in agreement with Viallon et al. [14] and confirm the high bias of the Hearn value [36]. These measurements are consistent with the more recent data depicted in Fig. 4. The measurement data in the figure can be interpreted as giving a bimodal distribution, with more recent values resulting in lower cross-section values.

\subsection{Conclusions}

After the first three ACSO meetings in 2009, 2010, and 2011 and evaluation of the available literature, it became clear that the ozone absorption cross-sections measured by the group in Reims (often called BDM, Refs. [1-4] and references therein) show very high consistency and fulfil most of the requirements for accurate laboratory data. Especially, they are available at high spectral resolution and different atmospheric temperatures for the Hartley and Huggins bands, they show smaller wavelength calibration errors compared to the data by Bass and Paur (often called BP, Refs. [5,6], and they cover a larger spectral range than Bass-Paur (BP). Also, extrapolation of this data to lower temperatures (i.e. $200 \mathrm{~K}$ and below) seems possible although the lowest available temperature is only $218 \mathrm{~K}$. For these reasons, the laboratory team of ACSO supports the recommendation to establish the ozone absorption cross-sections measured by the group in Reims [1-4] as new standard for atmospheric retrievals of ozone using the region around the Huggins bands (i.e. about 300-360 nm).

There are, however other problems and discussions. First of all, the team from BIPM pointed out that the existing value of Hearn [36] for the ozone absorption cross-section at the wavelength of the $\mathrm{Hg}$ line $(253.65 \mathrm{~nm})$ seems to be at the high end of the range of all measurements so far available. The Hearn value still serves as a standard reference however, see Viallon et al. [12], for calibrated surface ozone measurements, but a review of this value together with the possibility of adopting a new reference value and uncertainty has been initiated in the BIPM's Working Group on Gas Analysis (CCQM-GAWG). The most recent measurements by Viallon et al. [14] suggest a standard value (with an expanded uncertainty of $0.9 \%$ ) being $1.8 \%$ smaller than Hearn's. New measurements are needed to further narrowing down the range of the standard value (see Fig. 4). For this reason, it is important to underline that the assessment of the laboratory team of ACSO does not include a recommendation for the absolute value of the ozone absorption cross-section at the wavelength of the $\mathrm{Hg}$ line $(253.65 \mathrm{~nm})$ or its temperature dependence, but describes current practice, and it has to be noted that several of the UV-vis ozone cross-section data available have used the Mercury line value for scaling, as indicated in Fig. 4. As this practice leads to potentially $2 \%$ biases between datasets it should be resolved. Additional measurements with reduced uncertainties and/or based on dif-

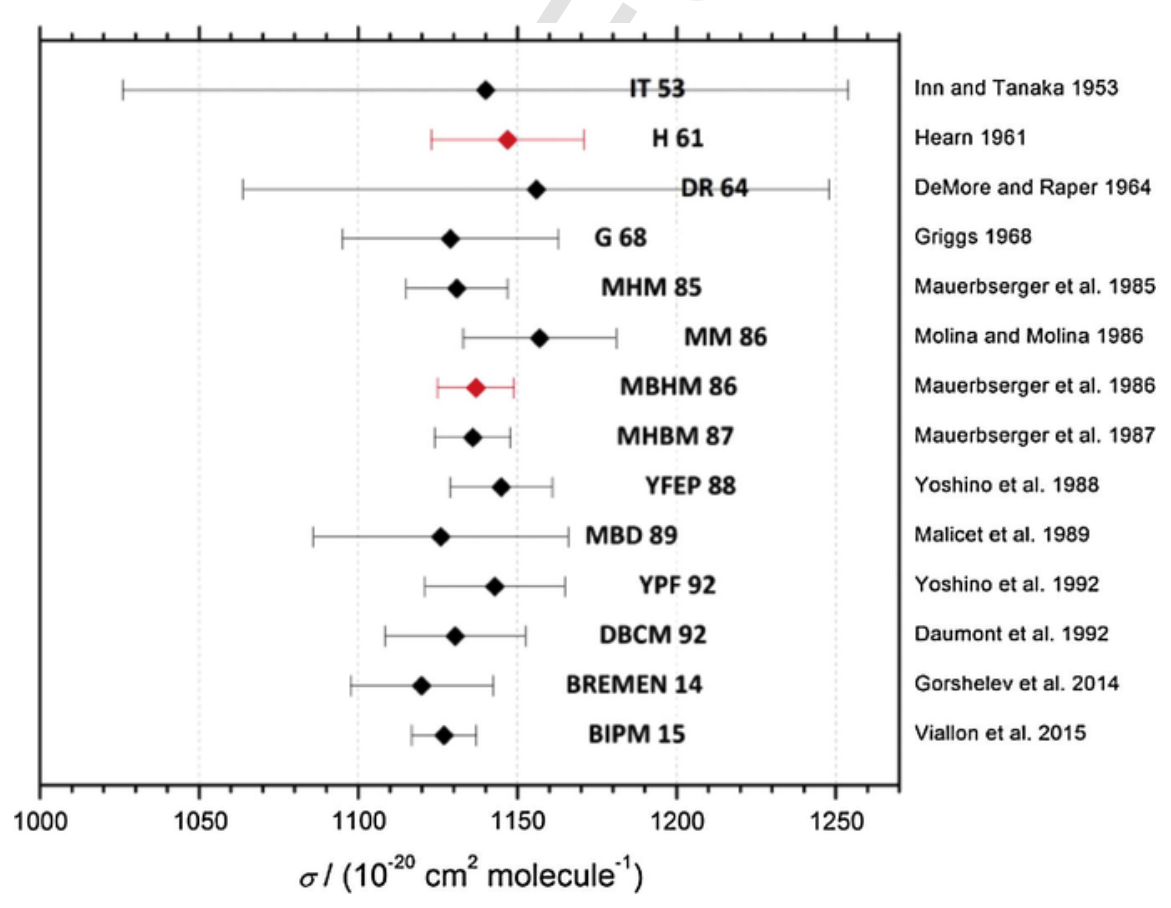

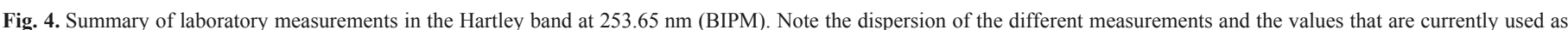

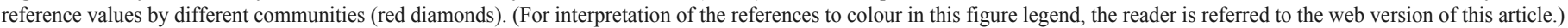


ferent methods, to eliminate method dependent biases, would be highly desired in order to identify the best methodology to derive the most representative value and uncertainty, see Petersen et al. [13] from the dataset.

Secondly, there is evidence from laboratory $[15,24,26]$ and field studies $[25,27,29]$ that there is a systematic difference between the absolute values of ozone absorption cross-sections in the ultraviolet (Hartley and Huggins bands) and mid-infrared line intensities (at room temperature), of about 4-5\%. However, individually, the ultraviolet-visible absorption cross-sections $[10,11,21]$ and mid-infrared line intensities $[22,23,39]$ are reported to be accurate to better than $2 \%$. Although this absolute difference of $4-5 \%$ seems to be statistically possible, it requires very urgent action (i.e. new laboratory measurements), since atmospheric retrievals using both spectral regions are seriously handicapped by this issue.

New laboratory measurements have been made during ACSO and have been published or publications are in preparations. These are the measurements (at room temperature) in the absorption minimum between the Huggins and Chappuis bands using Incoherent Broad Band Cavity Enhanced Absorption Spectroscopy (IBB-CEAS) [37,38], in the Hartley band using laser techniques $[13,31]$, or over a very large spectral range (from the UV to NIR) and different temperatures (starting at $193 \mathrm{~K}$ ) using a combination of Echelle and Fourier-Transform spectrometers [7,8]. In the extension phase of ACSO, the Serdyuchenko et al. cross-section data (often called SER, see Refs. $[7,8]$ have been to some extent evaluated for atmospheric applications as reported in Sections 3 and 4 and at the ACSO workshop in 2013. Depending on the instrumentation and wavelength ranges used, they show the potential of producing more consistent results than BDM. More laboratory measurements are currently underway, e.g. at DLR, GSMA and BIPM, supported in part by the European Space Agency/ European Space Research Institute (ESA-ESRIN) in the framework of Scientific Exploitation of Operational Missions (SEOM), at LERMA and GSMA, (supported by the French Centre National de la Recherche Scientifique - Les enveloppes fluides et l'environnement, Spectroscopie Multi-spectrale de l'Ozone: une étude intégrée du laboratoire à l'atmosphère (CNRS-LEFE-SMO3), and at the University of Bremen and LERMA, supported by the ATMOZ project and funded by the European Association of National Metrology Institutes (EURAMET) (ATMOZ) and the EMRP (European Metrological Research Programme)). Therefore, it is likely that a new assessment of the available $\mathrm{O}_{3}$ cross-sections will be required in the near future (i.e. 2017-2018).

\section{Summary of ground-based atmospheric ozone measurements of ACSO}

\subsection{Total ozone by Dobson and Brewer instruments}

Recommendation: To use the absorption cross-sections of [8] (SER, 2014) instead of those of Bass and Paur (1984) (BP 1984)

For retrieval of total ozone measurements of Dobson and Brewer instruments the use of laboratory measurements of ozone absorption cross-sections of SER (2014) provides the most satisfactory results as compared to those of Brion, Daumont, Malicet (BDM, 1995) and Bass and Paur (BP, 1984) (for comprehensive evaluation also including references of earlier studies see [66]. When replacing the presently used ozone absorption cross-sections of BP (1984) with BDM (1995) only a small effect on total ozone measurements of Dobson spectrophotometers (AD wavelength pair measurements, direct sun) is found, whereas the effect on retrieved column ozone amount of Brewer instruments is substantially larger (average reduc- tion by $3 \%$ ); this implies that the difference between collocated and simultaneous Dobson and Brewer column ozone measurements is becoming larger when using BDM (1995) instead of BP (1984). The discrepancy between AD-CD in Dobson measurements is similar when using BDM (1995) and BP (1984). However, when using the ozone absorption cross-sections of SER, 2014, Dobson and Brewer total ozone measurements are very similar and also the discrepancies between Dobson AD-CD wavelength pair data are smaller.

More realistic column ozone measurements can be obtained when introducing stratospheric temperature and temperature dependence of ozone absorption cross-sections into the retrieval of total ozone measurements of Dobson and Brewer instruments (by using ozone effective temperature), see Fragkos et al. [48] and Scarnato et al. [68]. The seasonal difference between Dobson and Brewer measurements reported earlier by applying the standard algorithms for Dobson and Brewer retrieval (using BP (1984) and ignoring temperature dependence of ozone absorption cross-sections) is becoming very small when introducing ozone effective temperature in the retrieval of total ozone measurements and temperature dependence of ozone absorption cross-sections provided by SER (2014).

\subsection{Ground-based ozone profile measurements by Umkehr and LIDAR}

\subsubsection{Umkehr (Dobson and Brewer)}

Recommendation: To use the absorption cross-sections of SER (2014) instead of those of BP (1984) when SER (2014) is used in total ozone retrieval.

Ozone cross-section changes (from currently used BP (1984) to BDM (1995) or SER (2014) only minimally (within the retrieval accuracy) affect the Dobson and the Brewer Umkehr retrievals. However, significantly larger errors are associated with out of-band (OOB) stray light contribution in the forward model of the Umkehr retrieval algorithm. The issues and methods of the OOB error correction has been originally described in Basher [40] and recently addressed in several papers $[47,59,65]$ (for more details see Petropavlovskikh et al. 2009 and 2013). In light of very small differences (within the uncertainty limits) in the retrieved ozone profiles introduced by the change of laboratory measurements of ozone absorption cross-sections it is recommended to use SER (2014) to have more consistency between profile and total ozone retrieval of Dobson and Brewer instruments.

In the Umkehr ozone profile retrieval [64] only climatological temperature profile [70] is used to apply corrections to the derived ozone profiles. Climatological temperature profile is selected based on the month of observation and the latitude of the station (10-degree zonal average). It is also weighted by the climatological ozone profile. Thus, method provides correction to only represent seasonal ozone changes, while it does not account for a year-to-year and long-term variability in stratospheric temperatures. For a middle latitude station the change to the profile is on the order of a few percent. However, it is possible that day-to-day variability in stratospheric temperatures is larger than represented by monthly and zonally averaged climatology, and therefore it could result in short-term variability in the derived Umkehr profiles. Thus, the corrections based on the daily temperature could potentially reduce the noise in the daily Umkehr retrieved profile record, but may not affect the monthly averages. However, it has not been quantified yet.

Further work is needed to study the effects of post-processing of the ozone profile data, when corrections to ozone column and profile data are based on the daily vs. climatological temperature profiles. The effect of using the long-term time series of temperature profiles 
for ozone data reprocessing would raise the question regarding the effect of the long-term corrections on the ozone trends.

\subsubsection{LIDAR}

The NDACC LIDAR group recommends to use either DBM (1995) or SER (2014)

The larger temperature range would favour the use of ozone absorption cross-sections of SER (2014) but non-monotonic variations in temperature dependence prevent to recommend SER (2014) for use in LIDAR measurements at the present time. Pastel et al. [62] report "a saw-tooth like variation with an amplitude of around $1.5 \%$ between 35 and $40 \mathrm{~km}$ altitudes (235-255 K)" when comparing BP (1984) with SER (2014), linked to the non-monotonic variations in SER (2014) cross-sections as a function of temperature.

In Pastel et al. [62] the effect of using ozone cross-section datasets from different spectroscopy laboratory measurements (namely BP (1984), BDM (1995) and SER (2013) was evaluated for the stratospheric and tropospheric ozone differential absorption lidar (DIAL). The change was analysed for the measurements based on both the Rayleigh and Raman scattering of the laser light by the atmosphere (the latter technique is essentially used for measurements performed in the presence of volcanic aerosol in the stratosphere). For stratospheric ozone measurements, the Committee on Space Research (COSPAR) International Reference Atmosphere [44] atmospheric model and a temperature climatology based on Modern-Era Retrospective Analysis for Research and Applications (MERRA) analyses have been used at various latitudes for the evaluation of ozone cross-section temperature dependence. Results show that the difference between the various datasets in both Rayleigh and Raman DIAL retrievals is below $2 \%$ in absolute values from 10 to $30 \mathrm{~km}$ for both CIRA and MERRA temperatures, with the largest differences found in the tropics and sub tropics in the lowermost stratosphere. Above
$30 \mathrm{~km}$, the difference estimated for the elastic DIAL retrieval only, is maximum around $45 \mathrm{~km}$, where it reaches $1.8 \%$ in the $\mathrm{BP}$ (1984)-BDM (1995) comparison. The ozone difference between these datasets and SER (2014) presents a systematic variation of about $1.2 \%$ from $35 \mathrm{~km}$ to $40 \mathrm{~km}$ especially in the tropics and sub-tropics. This variation is linked to noise issues in the SER (2014) dataset. For the measurements in the troposphere, the difference between ozone number densities retrieved with ozone cross-sections of BDM (1995) and BP (1984) is less than $2 \%$ below $250 \mathrm{~K}$ for the wavelength pairs $266 /$ $289 \mathrm{~nm}, 289 / 299 \mathrm{~nm}, 289 / 316 \mathrm{~nm}$ and is around $2 \%$ from $200 \mathrm{~K}$ to $293 \mathrm{~K}$ for the pair $285 / 291 \mathrm{~nm}$. Larger differences are found with the SER (2014) dataset. For the pairs 285/291 nm, 289/299 nm and 289/ $316 \mathrm{~nm}$, the differences range between $-2 \%$ and $-4 \%$ in the SER (2014)-BDM (1995) comparison and between $-2 \%$ and $-6 \%$ in the SER (2014)-BDM (1995) comparison in the whole temperature range. Differences are close to zero for the pair $266 / 289 \mathrm{~nm}$.

\section{Satellite measurements}

\subsection{Introduction}

As part of the ACSO activity we have studied the satellite-based ozone observations and their sensitivity to ozone absorption cross-sections. The work has been done in two phases. In the first phase we have studied whether the presently recommended ozone absorption cross-sections by Bass and Paur (BP, see Fig. 5) (Bass et al., 1985, Paur et al., 1985) should be changed to the more recently measured Brion, Daumont and Malicet (BDM, see Fig. 6) cross-sections [1-3]. In the second phase the use of the latest ozone absorption cross-sections by Serdyuchenko et al. (SER, see Fig. 8) [7,8] have been compared with retrievals using BDM and BP cross-sections. The main instruments considered here are SBUV, TOMS, OMI, SCIAMACHY

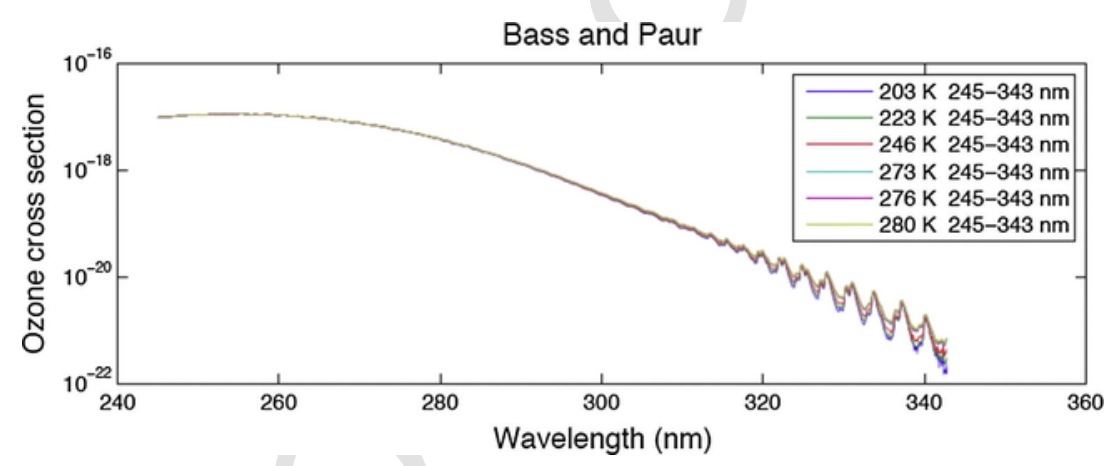

Fig. 5. Bass and Paur (BP) cross-sections.

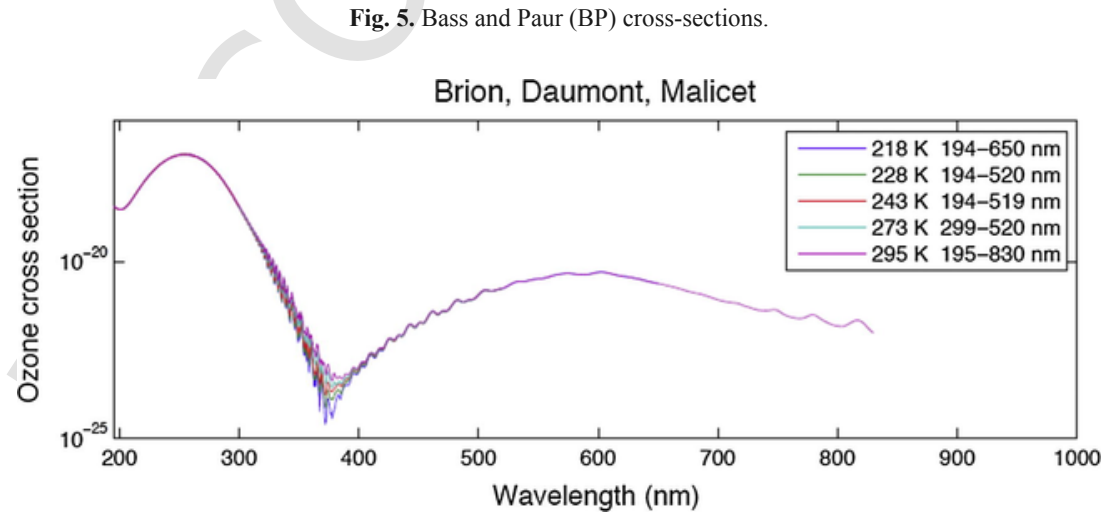

Fig. 6. Brion-Daumont-Malicet (BDM) cross-sections. 
and $\operatorname{GOME}(-2)$, which all use UV wavelengths to retrieve atmospheric ozone.

Both the SBUV ozone profile time series and the TOMS-OMI total ozone time series start in 1979. Both instruments are using UV wavelengths to derive ozone. Until recently the BP cross-sections have been used in the retrieval of these instruments (SBUV, TOMS and OMI). Presently BDM cross-sections are used for these instruments.

The time series of ozone profiles derived from UV nadir viewing sensors that started with SBUV have been complemented by measurements from GOME-1 (since 1995), OMI (since 2004), and GOME-2 (since 2007). In the past, total ozone retrievals from the European instruments GOME, GOME-2 and SCIAMACHY have mainly used cross-sections (in some cases modified) as measured by the instrument flight models prior to the launch: GOME-FM [43] and SCIA-FM (see [20]. The GOME-2 FM ozone cross-sections (Gür et al. 2006) and SCIA-FM (Fig. 7) have been recently been revised [33,34]. However, these updates have not been evaluated in this study except for a few cases for SCIAMACHY Version 4 data (SCIA-FM4). The GOME FM data [43] were mostly employed in the GOME-2 retrieval. Presently, some of the total ozone algorithms have already switched to the BDM data as a result of the studies presented here.

In addition to nadir looking instruments, limb and occultation instruments (Global Ozone Monitoring by Occultation of Stars (GOMOS), Optical Spectrograph and InfraRed Imaging System (OSIRIS), SCIAMACHY and SAGE II/III), which use VIS or a combination of UV and VIS wavelengths, have also been included in this study. These instruments provide ozone profiles with vertical resolution of $2-4 \mathrm{~km}$ in the stratosphere and mesosphere. The SAGE II high-resolution ozone profile time series that started in 1979 has recently been continued with other limb viewing and occultation measurements. GOMOS, OSIRIS and SCIAMACHY instruments all use Version 3 SCIAMACHY flight model (SCIA-FM) [20] cross-sec- tions. SAGE II cross-sections were changed during the ACSO work; until version 6.3 the Shettle and Andersson compilation (SAC) cross-sections [69] were used and SCIA-FM since version 7. SAGE III uses SCIA-FM cross-sections.

The variability in cross-sections used by different instruments causes differences in the ozone amounts from a few percent to some tens of percent depending on the instrument type. The requirement of measuring ozone to an accuracy of a few percent (e.g. in WMO's Global Climate Observing System (GCOS) requirements given in "Systematic observation requirements for satellite based data products for climate, 2011 Update" (GCOS-154) [50]) is so hard that all known sources of differences between instruments should be understood and removed as much as possible. In this respect, it is also important to understand and characterize the uncertainties in the ozone measurements originating from spectroscopy.

Each of the instruments/algorithms uses somewhat different wavelength regions, and therefore their sensitivities on cross-sections vary. Examples of wavelength regions are shown in Figs. 9 and 10. In addition, some retrieval algorithms are more sensitive to the absolute values of the cross-sections whereas others depend more on the relative differences (e.g. DOAS techniques). In particular, following topics have been studied:

- What are the differences in cross-sections and their temperature dependence at the wavelength region used in the retrievals?

- How different cross-sections affect the retrieved ozone densities?

- Do we improve the fitting residuals (potentially indicating better cross-sections)?

- Do we improve estimates of effective ozone temperature? In many retrieval algorithms it is possible to compute also a so-called effective temperature (i.e. mean atmospheric temperature weighted using the ozone concentration profile). It can be used to study the robustness of the retrieval when compared to correspondingly weighted (meteorological) re-analysis temperatures.

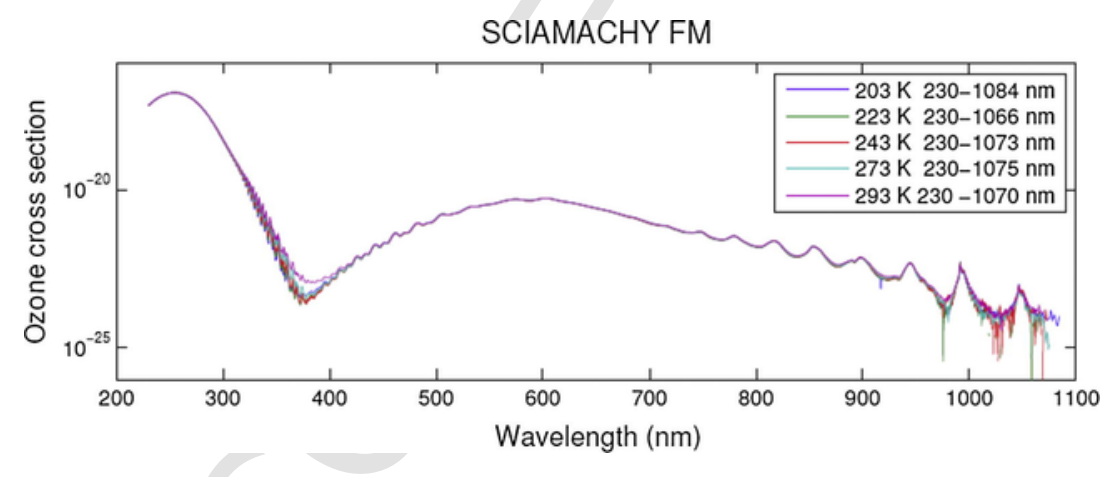

Fig. 7. SCIAMACHY flight model (SCIA-FM) [20], cross-sections.

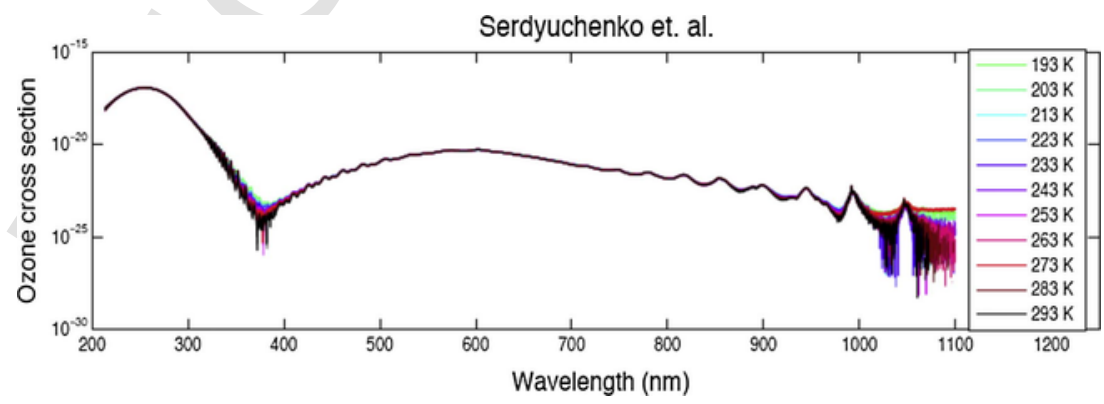

Fig. 8. SER cross-sections [8]. 


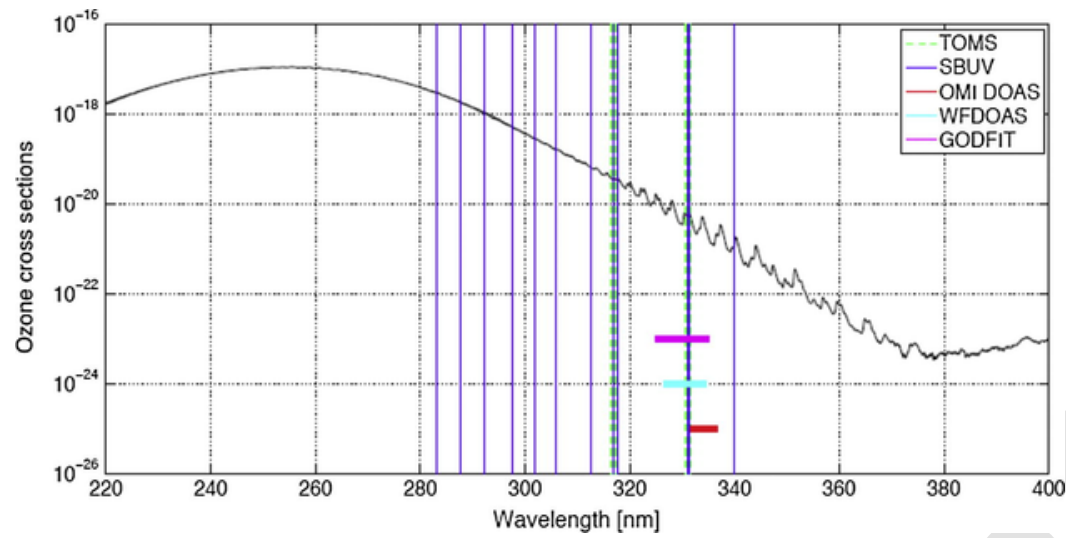

Fig. 9. Ozone cross-sections in one temperature (black line) and examples of wavelength regions used for instruments/algorithms providing total ozone.

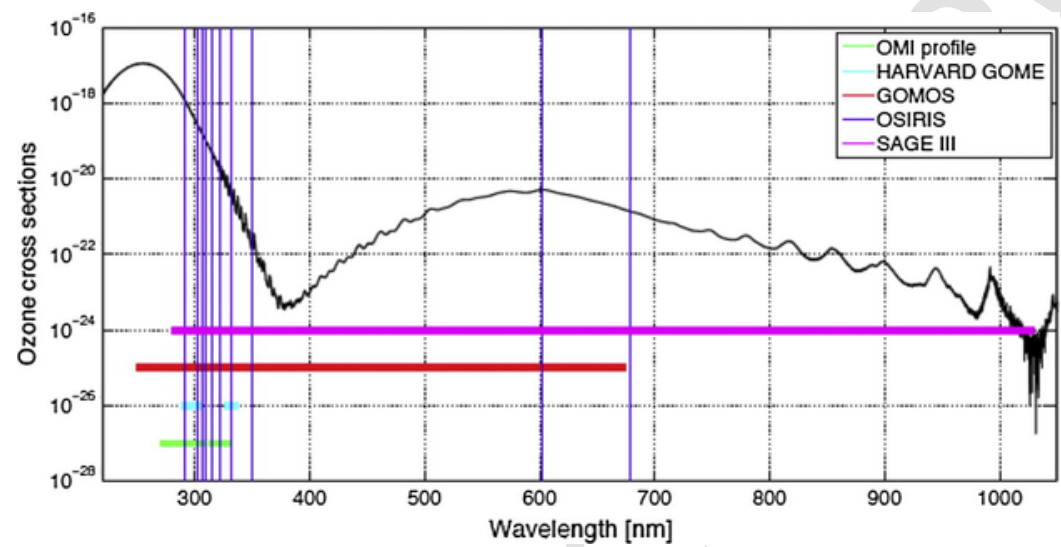

Fig. 10. Ozone cross-sections in one temperature (black line) and examples of wavelength regions used for instruments/algorithms providing ozone profiles.

- Do we observe differences in the agreement with ground-based measurements?

- Need for more laboratory measurements.

This summary report of the ACSO satellite sub-group is based on the workshop presentations and reports by the individual instrument and algorithm teams. The report is structured in the following way:

- Total ozone measurements of TOMS, OMI, GOME, GOME-2 and SCIAMACHY.

- Ozone profile measurements by nadir viewing SBUV, OMI, and GOME.

- High vertical resolution ozone profile measurements of SAGE II, SAGE III, OSIRIS and GOMOS.

- Summary and conclusions.

\subsection{Total ozone measurements}

The main techniques used for retrieving total ozone columns are:

- TOMS algorithm [60] uses measurements at $317 \mathrm{~nm}$ paired with $331 \mathrm{~nm}$ (adding longer wavelengths at high solar zenith angles) to derive ozone in an algorithm somewhat similar to the ground based Dobson algorithm. Details of the TOMS algorithm as applied to OMI are available in the OMI ozone Algorithm Theoretical Basis Document (ATBD), see http://www.knmi.nl/omi/documents/data/ OMI_ATBD_Volume_2_V2.pdf.
- DOAS (Differential Optical Absorption Spectroscopy) [63] technique is typically applied in two steps. In the first step the ozone slant column is derived by spectrally fitting differential absorption cross-sections directly to the observed optical density in a selected wavelength interval. In the second step the slant column is converted into vertical column amounts using air mass factors derived from modelling the radiative transfer in the measurement geometry. Algorithms based on DOAS technique include OMI DOAS, GDOAS (GOME) and SDOAS (SCIAMACHY).

- Direct fitting (e.g. $[45,55]$ ) is based on modelling the full radiative transfer according to the actual measurement geometry and fitting the vertical column in one step. This technique is applied in the GOME Direct-FITting (GODFIT) and Weighting Function Differential Optical Absorption (WFDOAS) algorithms. It primarily accounts for the wavelength dependence in the ozone air mass factor, which is usually calculated at a single representative wavelength in the standard DOAS retrieval.

\subsubsection{Total ozone measurements of TOMS and OMI using TOMS algorithm}

The backscatter UV (BUV) processing that has been applied to TOMS data since 1986 (i.e. versions 5-8) has been based on using the Bass and Paur (BP) ozone cross-sections. This TOMS algorithm is also applied to OMI to retrieve total ozone columns (OMTO3). A full reprocessing took place recently with algorithm v8.6 which is based on v8 ozone algorithm with BDM ozone cross-sections and a cloud height climatology based on OMI Raman and $\mathrm{O}_{2}-\mathrm{O}_{2}$ cloud re- 
trievals. This TOMS algorithm uses the B-pair (the $317 \mathrm{~nm}$ measurement paired with $331 \mathrm{~nm}$ ) at most latitudes. At these wavelengths the $\mathrm{BDM}$ cross-sections are $-1.3 \%$ smaller and thus the change from $\mathrm{BP}$ to BDM cross-sections causes an increase of about $2.3 \%$ in the total ozone values. At large zenith angles the increase is larger, around $3 \%$.

In the new v8.6 products also new cloud climatology is applied. It can cause ozone decreases of $2-4 \%$, depending on cloud cover and climatology change. The combined effect of cross-section change plus cloud climatology change is an average ozone increase of $1.5-2 \%$, depending on cloud cover.

The retrieval residuals are slightly better when using BDM. The BDM cross-sections are considered to be also more suitable for the new hyperspectral instruments (OMI, GOME, OMPS) because of their higher spectral resolution, broader wavelength coverage and their more accurate temperature dependence.

Preliminary studies indicate that change from BDM to SER cross-sections affects insignificantly to total ozone retrievals using TOMS algorithm. The relative differences in cross-sections at $317.5 \mathrm{~nm}$ and $331.2 \mathrm{~nm}$ are within $0.5 \%$.

\subsubsection{Total ozone measurements of OMI using DOAS method}

The OMI DOAS algorithm [73] uses fit window at 331.6-336.6 nm for total ozone retrieval. The difference between BP and DBM cross-sections is $\pm 1.5 \%$ with some spectral structure. The difference in temperature derivatives is larger up to $\pm 20 \%$. As the DOAS algorithm is sensitive to the relative difference between the cross-sections at the wavelength region used, the overall impact of changing from BP to BDM is quite small, on average the difference is about $0.5 \pm 1.7 \mathrm{DU}$. Individual changes are up to \pm 5 DU with standard deviation $\pm 2.5 \mathrm{DU}(<1 \%)$.

In the OMI DOAS algorithm the effective temperature is fitted simultaneously with the column ozone. When using BDM cross-sections, an improvement with respect to BP is observed in the agreement of the effective temperature compared to corresponding effective temperature computed using the European Center for Medium Range Weather Forecast (ECMWF) temperature data indicating improved inversion modelling. The residuals are, on the contrary, marginally worse when using BDM cross-sections.

Comparison of OMI DOAS total ozone retrieval using BDM with SER cross-sections shows that SER results in 3-4\% larger ozone columns. The difference depends on the solar zenith angle (larger with high SZA). The retrievals of the effective temperatures are comparable.

\subsubsection{Total ozone measurements by GOME, GOME-2 and SCIAMACHY using GDOAS and GODFIT algorithms}

The operational processing of total ozone columns of GOME (version GDP v4.1), GOME-2 (GDP v4.4) and SCIAMACHY (SGP v5.0) instruments is presently using GDOAS algorithm developed at BIRA-IASB [72]. The algorithm is based on using DOAS algorithm in the fitting interval $325-335 \mathrm{~nm}$. The base line of these operational retrievals is to use cross-sections measured with the corresponding flight model. Recently, a new version of the GOME-2 total ozone operational product (GDP v4.7) has been released, in which one of the important upgrades is to use the BDM data instead of the flight model cross-section. During the recent years an improved direct fitting algorithm, GODFIT has also been developed and provides more accurate results at high latitudes. As a base line, BDM cross-sections are used in the GODFIT algorithm. GODFIT is the algorithm used within the ESA Ozone Climate Change Initiative (CCI) project to generate multi-sensor total ozone datasets. In particular, the GOME, SCIA-
MACHY and GOME-2A datasets have been recently fully reprocessed [55]. The latest version of the GOME/ERS-2 operational product (GDP v5) is also based on GODFIT.

In the first phase of the ACSO BP, BDM, GOME-FM and SCIA-FM were studied. In the wavelength range used for GDOAS and GODFIT algorithms the amplitude of the BP and BDM differential cross-sections agree within 1\% while the GOME-FM differential cross-sections are $1.7-3.7 \%$ larger. The difference is reflected in the (GODFIT) retrieved ozone values in following way: the total ozone values using $\mathrm{BP}$ and $\mathrm{BDM}$ cross-sections are within $0.5 \%$ and when using GOME-FM cross-sections the ozone values are $2-3 \%$ smaller than when using BP or BDM.

The DOAS algorithm contains an option to pre-shift the cross-sections to compensate possible wavelength registration errors. The test cases show that, on average, BP cross-sections need to be shifted with $0.023 \mathrm{~nm}$ and GOME-FM with $0.017 \mathrm{~nm}$ while BDM cross-sections shows accurate registration and does not need to be shifted. This indicates good wavelength registration in BDM cross-sections.

The residual analysis shows that BP cross-sections lead systematically to higher residuals for GOME, SCIAMACHY and GOME-2 retrievals. The residuals of BDM and GOME-FM are similar for GOME-2 and SCIAMACHY while BDM gives the smallest residuals for GOME.

By analysing the fitted effective temperatures it is observed that BP gives systematically lower effective temperature (few degrees) values than GOME-FM and BDM. For the GOME instrument BDM results in the highest (few degrees higher than GOME-FM) temperatures. Comparison with ECMWF temperatures shows that effective temperatures obtained using BDM cross-sections in GOME retrieval agree well with weighted ECMWF temperature values indicating that the temperature dependence of BDM cross-sections is accurate enough.

From the previous intercomparison exercise, the BDM cross-sections were selected as the baseline for retrieving total ozone with GODFIT. The University of Bremen has released a new ozone absorption cross-section dataset (Serdyuchenko et al.) in 2013, the quality of this new dataset has been assessed and its impact on GODFIT total ozone retrievals has been evaluated. Both datasets (DBM and SER) have been found to have similar and high wavelength registration quality, at least for the temperatures relevant for total ozone retrievals (200-260 K). From the point of view of the fit residuals, both datasets behave also similarly. On average, the SER cross-sections lead to total ozone columns $1-2 \%$ larger than the BDM data, depending on the temperature conditions. These differences are explained by slightly smaller differential structures for the SER data and also by slightly different temperature dependence. However, the agreement of the retrieved effective temperatures with effective temperatures computed using ECMWF is not found to be systematically better with one of the two datasets.

\subsubsection{Total ozone measurements by GOME, GOME-2 and \\ SCIAMACHY using the WFDOAS algorithm}

At the University of Bremen, the WFDOAS algorithm has been developed to retrieve total ozone columns from GOME, GOME-2 and SCIAMACHY $[42,45,75]$. The fitting window used in the WFDOAS is $326.6-334.5 \mathrm{~nm}$ (for GOME the upper limit is $335 \mathrm{~nm}$ ). The base line of the WFDOAS algorithms is to use the flight model cross-sections. When comparing the cross-sections directly it is observed that the SCIA-FM cross-sections at absorption maximum is smaller than GOME-FM although the spectral resolution are almost identical. This results in a scaling difference of 5\% (difference between absorption maximum and minimum) between SCIAMACHY 
FM and GOME FM in the WFDOAS fitting window. The GOME-FM cross-sections have a scaling difference of $2-3 \%$ with respect to BDM. This results for both BP and BDM 2-3\% higher total ozone retrieved compared to the use of GOME-FM in the WFDOAS retrieval.

Possible wavelength shifts in the cross-section data can be estimated by minimising the spectral fit residuals in the ozone retrieval. It shows that the wavelength calibration of BDM is good and no shift is needed, SCIA-FM needs to be shifted by $+0.014 \mathrm{~nm}$ and GOME-FM by +0.017 . The direct comparisons of cross-sections yielded shifts of $+0.009 \mathrm{~nm}$ for SCIAMACHY FM and $+0.017 \mathrm{~nm}$ for GOME FM with respect to BDM. The residuals of $\mathrm{BP}$ are systematically worse than BDM and satellite FM. For GOME-2 BDM residuals were slightly better than GOME-FM. For SCIAMACHY the BDM residuals are similar and at high solar zenith angles slightly better than SCIA-FM.

For creating a merged GOME-SCIAMACHY-GOME-2 dataset $[51,76]$ it is important that consistent cross-section data are used. For the WFDOAS retrievals GOME-FM cross-sections with a $+0.017 \mathrm{~nm}$ shift and no scaling are used for GOME, SCIA-FM cross-sections (Bogumil et al.) shifted by $+0.009 \mathrm{~nm}$ and scaled by $+5.3 \%$ for SCIAMACHY, and slit function convolved GOME-FM cross-sections with a shift of $0.017 \mathrm{~nm}$ for GOME-2. Due to calibration uncertainties that differ for the various satellite instruments some biases may still remain and they are usually on the order of a few percent.

Very recently it was shown that revised cross-section data (Version 4) from SCIAMACHY FM (SCIA-FM4) show better agreement with the standard WFDOAS retrieval [33]. Similarly the retrieval used with the GOME2 FM3 (now flying on Metop A) cross-sections [34] show now consistent results with the GOME-2 retrieval using convolved GOME-FM cross-sections. All satellite FM cross-section data (incl. the revised ones) show very similar spectral fit residuals if appropriate wavelength shift corrections are applied to them $[33,34]$.

The direct comparison of the SER cross-sections to BP and BDM shows that in the WFDOAS fitting window the SER cross-section differences between absorption maxima and minima are slightly smaller than both BP (ratio $1.0 \%$ larger) and BDM (ratio $1.4 \%$ larger). This difference means that the Serdyuchenko et al. cross-sections in the WFDOAS total ozone retrieval will yield approximately $1.5 \%$ higher total ozone compared to BP and BDM, respectively.

The BDM, BP, and Serdyuchenko cross-sections have been compared in a WFDOAS total ozone retrieval applied to GOME-2 spectral data. The results can be summarized as follows:

- Spectral fit residuals using BDM and SER data are lower than BP.

- BP spectral fit residuals gets reduced if the BP are shifted by $+0.029 \mathrm{~nm}$, but remain higher than BDM and SER.

- SER retrieved total ozone is on average $\sim 1.5 \%$ higher than BMD and wavelength shifted Bass Paur.

- BDM and wavelength shifted Bass Paur agree within 0.5\%.

- Ozone results are as expected from the direct comparisons between cross-sections.

Sensitivities of ozone differences with respect to the retrieved effective ozone temperature varies and are on the order of $-1 \%$ to $+1 \%$ DU per $20 \mathrm{~K}$ change between BMD, BP and SER cross-sections.

\subsection{Ozone profiles using nadir viewing instruments}

The nadir viewing instruments SBUV, OMI, GOME(-2), and SCIAMACHY which measure the radiance at several wavelengths include also information about the vertical distribution of the ozone concentration. The retrieval problems are strongly ill-posed implying that some additional information (regularization or prior information) is required in order to successfully retrieve ozone profiles from the limited amount of information. Most commonly used algorithms are based on two techniques:

- SBUV technique [41] is based on the fact that sunlight at wavelengths near $250 \mathrm{~nm}$ only penetrates to the upper stratosphere, while longer wavelengths $(270-310 \mathrm{~nm})$ penetrate further and further into the atmosphere. Thus, a wavelength scan is equivalent to an altitude scan. SBUV technique is based on using discrete wavelengths for the retrieval.

- Optimal estimation technique [67]: It is based on Bayesian approach on treating the measurements and unknowns as random variables and describing the solution as a posterior distribution that takes into account the likelihood and the available prior information. In practice, the nonlinear problem is solved iteratively and the posterior distribution is characterized by providing the estimate and the error covariance matrix. The profile retrievals based on optimal estimation method use radiance spectra of the fitting window for the retrieval.

\subsubsection{Ozone profile measurements by SBUV}

The series of SBUV instruments, flown by NASA and NOAA since 1978, measure ozone profiles with 5-10 km resolution. The present V8 algorithm has been optimized to produce, in particular, a dataset for trend analysis and to maintain the long-term calibration as good as possible.

The SBUV instruments measure at 12 wavelengths [255.65, $273.61,283.10,287.70,292.29,297.59,301.97,305.87,312.56$, $317.56,331.26,339.89]$. The profile retrieval uses wavelengths below $306 \mathrm{~nm}$, adding longer wavelengths at large zenith angles for better penetration. The SBUV processing versions 5-8 used the BP ozone cross-sections. As with TOMS and OMI, a v8.6 processing has recently taken place in which all the data from the $\operatorname{SBUV}(/ 2) \mathrm{se}-$ ries has been processed using the BDM cross-sections. The difference between BP and BDM slit averaged cross-sections is slightly negative ( -0.3 to $1.6 \%$, BDM larger) below $284 \mathrm{~nm}$ and slightly positive $(0.5-1 \%$, BDM smaller) between $284 \mathrm{~nm}$ and $306 \mathrm{~nm}$. These differences cause an ozone decrease of about $2-4 \%$ in the upper stratosphere but an increase of $1-2 \%$ in the middle stratosphere, depending on latitude and solar zenith angle. The combined effect on the integrated column ozone is a decrease of about a percent, except at high solar zenith angles where there is an increase of $1-2 \%$. Notice that the effect of using BDM cross-sections is an ozone increase (of about $1.5 \%$ ) for TOMS and OMI but and ozone decrease (of about 1\%) for SBUV. This is due to the fact that shorter wavelength cross-sections (250-306 $\mathrm{nm}$ ) are used for the SBUV profile retrievals while longer wavelengths $(317-340 \mathrm{~nm})$ are used for the TOMS and OMI retrievals.

The agreement of SBUV total ozone measurements with Brewer/ Dobson measurements shows a clear solar zenith angle dependence when using BP cross-sections while the dependence vanishes when using BDM cross-sections. This indicates that the BDM cross-sections are more accurate. The residual analysis does not show any significant changes when changing from BP to BDM.

In addition to the accurate absolute values and wavelength registration, the temperature dependence of the cross-sections is very important, especially when ozone profiles and tropospheric ozone are retrieved. The BP and BDM cross-sections show very different temperature dependence: the $\mathrm{max} / \mathrm{min}$ temperature dependence of BDM coincides with the $\mathrm{max} / \mathrm{min}$ of the cross-sections while for BP this is not the case. This suggests that there has been problems in maintain- 
ing the wavelength consistency during the laboratory measurements of $\mathrm{BP}$ cross-sections.

Preliminary results show that the SER cross-sections do not agree well with BDM or BP cross-sections below $300 \mathrm{~nm}$ where the relative differences are up to 3\%. At longer SBUV wavelengths the differences are insignificant. It is expected that the discrepancy at shorter wavelengths would affect the retrieved ozone profiles particularly at upper stratosphere. Presently, when using the BDM cross-sections, the agreement with SBUV and Aura/Microwave Limb Sounder (MLS) is very good at this altitude region.

\subsubsection{Ozone profile measurements by OMI}

The KNMI team applies the optimal estimation technique to retrieve the ozone profiles at 18 layers with $5-10 \mathrm{~km}$ resolution from OMI nadir measurements. The wavelength bands 270-308.5 (OMI UV-1) and 311.5-330 (OMI UV-2) are used for the retrieval. The baseline cross-sections are BDM. The a priori ozone profiles are from Labow, Logan, McPeters [61] with 20\% error and $6 \mathrm{~km}$ vertical correlation length.

A test with more than 120,000 profiles indicates that the difference in total column ozone is small, $-1 \pm 3 \mathrm{DU}(-1.3$ to $0.3 \%)$, when changing from BP to BDM (i.e. BDM results are typically slightly less than BP). The difference at specific layers varies, and can be $10-15 \%$ increasing towards the troposphere.

The tests showed that the BDM residuals are significantly better than BP. Also, the reflectance cost function indicates that the BDM cross-sections are better.

The OMI profile retrievals with the new SER cross-sections indicate differences in ozone densities up to $20 \%$ at some layers compared to BDM cross-sections. The differences show oscillations with respect to pressure and for some layers the differences seem to correlate with temperature. This indicates differences in the temperature dependence of the BDM and SER cross-sections. The convergence and fitting diagnostics are similar in both cases.

\subsubsection{Ozone profile and column measurements by GOME and OMI using the HARVARD algorithm}

The algorithm developed at the Harvard-Smithsonian Center for Astrophysics, noted as Harvard algorithm here, has been used to study the effect of various cross-sections in ozone profile retrievals using UV measurements of GOME and OMI. The algorithm is based on optimal estimation technique with a priori climatology from McPeters et al. [61].

\subsubsection{Harvard algorithm in GOME retrieval}

The impact of using different cross-sections (BP, BDM and GOME-FM) for retrieving ozone profiles from GOME data was published in Liu et al. [56]. The tests were made using fitting windows 289-307 nm and 326-337 nm for retrieving ozone profiles at 24 layers. The systematic difference in BP and BDM in the first fitting window is about $1 \%$ with small mean biases. In the second fitting window $\mathrm{BP}$ cross-sections are higher by $1-2 \%$ than BDM. The differences are temperature dependent. The impact on the ozone retrievals show that total ozone retrieved with BDM are, on average, larger by 1-2 DU than those by BP, with a maximum of 5 DU. The impact on tropospheric ozone is on average $3-15 \%$ (maximum $10 \mathrm{DU}$ ) and the mean ozone profiles below $12 \mathrm{~km}$ are larger by $7-15 \%$ when using BDM.

The fitting residuals at $289-307 \mathrm{~nm}$ show slight improvement when using BDM cross-sections compared to BP. In the second fitting window the improvement was significant. The GOME-FM cross-sections show slightly better agreement with BP than with
BDM in both cases. The residual analysis also showed that the mean fitting residuals for 326-337 nm with BDM cross-sections do not vary with latitude or solar zenith angle suggesting better temperature dependence in the BDM data.

The geophysical validation of tropospheric column ozone at Hohenpeissenberg and Hilo showed that BDM agrees generally better with ozone soundings, having smaller bias and standard deviation and higher correlation coefficient than BP.

\subsubsection{Harvard algorithm in OMI retrieval}

The comparison of three datasets of high-resolution ozone cross-sections (BP, BDM and SER) and the evaluation of the impact of using different cross-sections for retrieving ozone profiles from OMI UV data was published in [58]. The tests were made using fitting windows $269-309 \mathrm{~nm}$ and $312-330 \mathrm{~nm}$ for retrieving ozone profiles at 24 layers.

The study shows that relative to the BDM dataset, the SER data have systematic differences of -2 to $+4 \%$ for $260-340 \mathrm{~nm}$, and the BP data have smaller differences of $1-2 \%$ below $315 \mathrm{~nm}$ but larger spiky biases of up to $\pm 6 \%$ at longer wavelengths. These datasets show distinctly different temperature dependences.

The fitting residuals of BDM and SER are similar, which indicates similar wavelength calibration and precision for the datasets. The fitting residuals of BP are much larger in the second fitting window suggesting wavelength dependent errors. When using the SER data the Harvard retrieval fails for almost half of the OMI spatial pixels due to large negative ozone values at some layers that cannot be handled by radiative transfer models.

Relative to the BDM retrievals, total ozone retrieved using the original SER data (with linear temperature interpolation/extrapolation) typically shows negative differences of 5-10 DU; retrieved tropospheric ozone column generally show negative biases of 5-10 DU and 5-20 DU for parameterized and original SER data, respectively.

Compared to BDM retrievals, ozone profiles retrieved with BP and SER data show, on average, large altitude-dependent oscillating differences of up to $\pm 20-40 \%$ below $\sim 20 \mathrm{~km}$ with almost opposite patterns. Validation with ozonesonde observations demonstrates that the BDM retrievals agree well with ozonesondes, to typically within $10 \%$, while both BP and SER retrievals consistently show large altitude-dependent biases of up to $\pm 20-70 \%$ below $20 \mathrm{~km}$. Based on their study, the BDM dataset is recommended for ozone profile retrievals from UV measurements. Its improved performance is likely due to its better characterization of temperature dependence in the Hartley and Huggins bands.

\subsection{High resolution ozone profiles using limb and occultation instruments}

The UV-vis occultation and limb viewing instruments typically use Hartley-Huggins and Chappuis bands to retrieve ozone profiles. The most commonly used cross-sections at the moment are SCIA-FM cross-sections (version 3 ) which cover the required wavelength region with good spectral resolution. The latest revision, Version 4, of SCIAMACHY flight model cross-sections have only been studied in SAGE II retrievals.

\subsubsection{Ozone profile measurements by GOMOS}

GOMOS stellar occultation instrument uses the UV-vis fitting window at $250-675 \mathrm{~nm}$ to retrieve ozone profiles with $2-3 \mathrm{~km}$ resolution from 10 to $100 \mathrm{~km}$ altitude range. The algorithm (Kyrölä et al., 2010) is two-step algorithm: first horizontally integrated densities of 
ozone and some other constituents are retrieved and in the second step the vertical profiles are constructed. No prior information about ozone density is used in the retrieval except that Tikhonov type of regularization is applied assuming $2-3 \mathrm{~km}$ smoothness of the profiles. The base-line algorithm uses SCIA-FM cross-sections with linear temperature dependence.

In GOMOS retrieval also the VIS wavelengths are needed and therefore BP cross-sections have not been tested. For BDM the VIS wavelengths are only available in one temperature $295 \mathrm{~K}$. At the GOMOS fitting region the difference between BDM cross-sections at $295 \mathrm{~K}$ and SCIA-FM cross-sections at $293 \mathrm{~K}$ are $\pm 1-5 \% \mathrm{BDM}$ cross-sections often lower than SCIA-FM. The difference in the ozone values at the retrieval layers is $0-1.5 \%$ BDM resulting higher ozone values. The differences are altitude dependent, being largest $(1.5 \%)$ around ozone maximum $20-30 \mathrm{~km}$ and smallest around $50 \mathrm{~km}$ while at high altitudes above $60 \mathrm{~km}$ the difference is around $1 \%$. The residual analysis does not show clear evidence which one of the datasets is better.

For GOMOS instrument the BDM dataset is not suitable because wider temperature and wavelength coverage is needed. The temperature and wavelength coverage of the recent SER cross-sections are good and thus also potentially suitable data for GOMOS.

In the wavelength region used for GOMOS retrieval the SER cross-sections are generally smaller (up to $10 \%$ ) than the SCIA-FM cross-sections except for the region $265-295 \mathrm{~nm}$ and at some wavelengths in $300-370 \mathrm{~nm}$. GOMOS ozone profiles retrieved using the SER cross-sections show larger ozone values than the retrievals using SCIA-FM cross-sections in the altitude region $70-100 \mathrm{~km}$ where the difference is below $1 \%$ and below $45 \mathrm{~km}$ where the difference is about $2 \%$. In the altitude region $45-75 \mathrm{~km}$ ozone using SER cross-sections is about $2 \%$ smaller than when using SCIA-FM cross-sections. These results vary to some extent depending on the spectral class of the star used in the GOMOS measurement.

\subsubsection{Ozone profile measurements by OSIRIS}

The Canadian built Optical Spectrograph and InfraRed Imaging System (OSIRIS) is a limb viewing instrument that measures scattered sunlight over a wide range of UV-vis wavelengths. These measurements are used to retrieve ozone and other constituents. The so-called Chappuis triplet algorithm and additional UV and blue wavelength pairs are used at University of Saskatchewan to retrieve ozone profiles below $55 \mathrm{~km}$ [46]. Radiance measurements at $543.84 \mathrm{~nm}, 602.39 \mathrm{~nm}$ and $678.85 \mathrm{~nm}$ are used to retrieve ozone in the upper troposphere and lower stratosphere while measurements at wavelengths near $292 \mathrm{~nm}$, $302 \mathrm{~nm}, 306 \mathrm{~nm}, 310 \mathrm{~nm}, 315 \mathrm{~nm}, 322 \mathrm{~nm}, 331 \mathrm{~nm}$ and $350 \mathrm{~nm}$ are used to retrieve ozone in the altitude range from $25 \mathrm{~km}$ to $55 \mathrm{~km}$.

Absorption of limb scattered sunlight by ozone is significant at all of these wavelengths except for $350 \mathrm{~nm}$. The cross-sections used by the OSIRIS Team are currently the SCIA-FM values.

The impact of using other cross-sections was studied in some test cases which showed that the BDM cross-sections result in about $1.5 \%$ more ozone at $25-35 \mathrm{~km}$ region compared to BP while at other altitude regions the difference is less than $1 \%$. The difference between SCIA-FM and BDM is larger: SCIA-FM results up to $4 \%$ less ozone around the ozone maximum than BDM. Further work showed that the retrieved results varied in an insignificant fashion when either the BDM or the SER cross-sections were used.

\subsubsection{Ozone profile measurements by SAGE II/III}

The SAGE instruments have measured high-resolution ozone $\mathrm{NO}_{2}$, $\mathrm{H}_{2} \mathrm{O}$ and aerosol profiles since 1979 using solar occultation technique (SAGE 1979-81, SAGE II 1984-2005) at 9 wavelengths between 384 and $1545 \mathrm{~nm}$. The hyperspectral SAGE III instrument has continued these measurements with broader spectral region covering 280-1030 nm. SAGE III has two main ozone products: mesospheric profile $60-100 \mathrm{~km}$ and stratospheric/tropospheric profile from cloud top to $60 \mathrm{~km}$. While the SAGE II ozone profiles are retrieved using only the VIS-NIR region, SAGE III uses also the UV channels at 284, 290, and $296 \mathrm{~nm}$ for mesospheric ozone. The current SAGE II (version 7) SAGE III algorithm (version 4) use SCIA-FM cross-sections. Up till SAGE II Version 6.3 Shettle and Andersson compilation (SAC) cross-sections were used (Shettle and Andersson, 1994). The earlier versions of SAGE III used SAC at longer wavelengths and BP at UV.

The difference in the BDM and SCIA-FM cross-sections at the SAGE III mesospheric channels are found to differ from $-0.5 \%$ (BDM larger than SCIA-FM) to 1\% (SCIA-FM larger than BDM). This leads to a small $(\max 1 \%)$ difference in the mesospheric ozone, which is negligible compared to the estimated precision of the product. The SAGE III ozone profiles below $55 \mathrm{~km}$ are retrieved using Chappuis absorption band centred near $600 \mathrm{~nm}$. At this wavelength region BDM cross-sections are smaller than those by SCIA-FM by about $1 \%$ (at $295 \mathrm{~K}$ ). This would lead to about $1 \%$ larger ozone concentrations than with the present algorithm using SCIA-FM.

For SAGE II the change from SAC to SCIA-FM was estimated to result in about $2 \%$ decrease in the retrieved ozone concentration. The change from SAC to BDM was approximated to be about $1 \%$ reduction in the retrieved ozone.

SAGE III instrument requires a consistent ozone cross-sections for the wide wavelength band up to Wulf band in NIR in order to correctly remove the ozone signature from the water vapour $(940 \mathrm{~nm})$ and aerosol bands. Therefore, consistent laboratory measurements to verify the temperature dependence over 190-300 K in the Chappuis-Wulf and Hartley-Huggins bands are important. In this respect, the recent SER cross-sections could potentially be suitable for SAGE III.

The resent SER and SCIA-FM4 cross-sections have been studied using the SAGE II algorithm in Chappuis band used for stratospheric ozone. In this wavelength region the SER cross-sections are about $4 \%$ lower than SCIA-FM. As a result, the SER data lead to about $2-3 \%$ larger ozone number densities compared to SCIA-FM. Similar changes are expected in SAGE III ozone. The latest SCIA-FM4 cross-sections show different changes in this wavelength region where the cross-sections increase about $2 \%$ compared to SCIA-FM. This leads to ozone number densities $2-4 \%$ smaller than when using SCIA-FM. Similar changes are again expected in SAGE III ozone. These differences are considered to be significant. For SAGE $\mathrm{H}_{2} \mathrm{O}$ retrievals ozone cross-sections are also needed in the Wulf band where the differences between SCIA-FM and SER and also SCIA-FM4 and SCIA-FM are surprisingly large, typically $10-20 \%$. Such differences lead to large (5-10\%) differences in $\mathrm{H}_{2} \mathrm{O}$ profiles. These spectroscopic differences need to be understood better, thus additional laboratory measurements are needed to reduce the uncertainty in visible and NIR cross-sections (especially Wulf bands).

\subsection{Summary}

The satellite sub-group of ACSO has studied the sensitivity of satellite retrievals on various existing ozone absorption cross-sections. The aim of this work has been to evaluate the suitability of various cross-sections for the individual retrievals and to analyse the differences caused by differences in spectroscopic data. The retrieval characteristics including residuals and effective temperatures have 
been analysed. Both total ozone columns and ozone profiles have been included in this work.

The effect of changing cross-sections from BP to BDM is generally small for DOAS/Direct-fitting type of algorithms. For TOMS retrievals, such a change leads to an increase of $1-2 \%$ in total ozone, while for SBUV the effect in total ozone column is slightly negative. For limb viewing and occultation instruments the ozone retrievals using BP/SCIA-FM and BDM cross-sections differ typically $1-4 \%$ at individual layers. Larger differences $(\sim 10 \%)$ at individual layers are observed with nadir viewing instruments. The effects are summarized in Table 1 below.

Table 1

Summary of the compared algorithms and the impact of changing cross sections

\begin{tabular}{|c|c|c|c|}
\hline Instrument/algorithm & $\begin{array}{l}\text { Baseline up } \\
\text { till now/ } \\
\text { compared to }\end{array}$ & $\begin{array}{l}\text { Difference } \\
\text { compared to BDM }\end{array}$ & $\begin{array}{l}\text { Difference compared } \\
\text { to SER }\end{array}$ \\
\hline \multicolumn{4}{|l|}{ Total ozone columns } \\
\hline TOMS & $\begin{array}{l}\text { BP } \\
\text { BDM version } \\
8.6\end{array}$ & $\begin{array}{l}+1.5 \text { to }+2 \% \text { (vs. } \\
\text { BP) }\end{array}$ & $< \pm 1 \%($ vs. BDM $)$ \\
\hline OMI DOAS & $\mathrm{BP}$ & $\begin{array}{l}<1 \% \text { on average } \\
(\operatorname{std} 2.5 \%)\end{array}$ & 3-4\% (vs. BDM) \\
\hline GODFIT & $\begin{array}{l}\text { GDOAS } \\
\text { (GOME-FM) } \\
\text { GODFIT } \\
\text { baseline } \\
\text { BDM }\end{array}$ & $+2-3 \%$ & $+1-2 \%$ (vs. BDM) \\
\hline WFDOAS & $\begin{array}{c}\text { GOME-FM } \\
\text { SCIA-FM }\end{array}$ & $+2.5 \%$ & $+1.5 \%(\mathrm{vs} . \mathrm{BDM})$ \\
\hline \multicolumn{4}{|l|}{ Nadir profiles } \\
\hline SBUV profile & $\begin{array}{l}\text { BP } \\
\text { re- } \\
\text { proccessing } \\
\text { BDM }\end{array}$ & $\begin{array}{l} \pm 5 \% \\
-2 \text { to }-4 \% \text { upper } \\
\text { strat. } \\
+1 \text { to }+2 \text { middle } \\
\text { strat. } \\
\text { Tot about }-1 \%\end{array}$ & $\begin{array}{l}\text { Significant differences } \\
\text { (of few \%) expected } \\
\text { at upper stratosphere } \\
\text { compared to BDM }\end{array}$ \\
\hline OMI profile & Baseline BDM & $\begin{array}{l}\sim 20 \% \text { at layers } \\
1 \% \text { total average }\end{array}$ & $\begin{array}{l}\text { Oscillating differences } \\
\text { up to } 20 \% \text { at some } \\
\text { layers compared to } \\
\text { BDM }\end{array}$ \\
\hline $\begin{array}{l}\text { Harvard algorithm } \\
\text { GOME profile }\end{array}$ & BP vs. BDM & $\begin{array}{l}0.5 \% \text { column } \\
1-2.5 \% \text { trop. } \\
\text { column } \\
\text { Large difference } \\
\text { at individual } \\
\text { layers (up to } \\
100 \% \text { in low } \\
\text { ozone conditions) }\end{array}$ & \\
\hline $\begin{array}{l}\text { Harvard algorithm } \\
\text { OMI profile }\end{array}$ & & $\begin{array}{l}\text { BDM compared to } \\
\text { BP: } \\
\text { Altitude } \\
\text { dependent } \\
\text { oscillations } \\
\pm 20-40 \%\end{array}$ & $\begin{array}{l}\text { Compared to BDM: } \\
-1 \text { to }-4 \% \text { ( }-5 \text { to }-10 \\
\text { DU) column } \\
-5 \text { to }-20 \% \text { trop. } \\
\text { column } \\
\text { Altitude dependent } \\
\text { oscillations } \\
\pm 20-40 \% \text { (opposite } \\
\text { sign as BP) }\end{array}$ \\
\hline \multicolumn{4}{|l|}{ Limb/occ. profiles } \\
\hline GOMOS & SCIA-FM & 0 to +1.5 & $\begin{array}{l} \pm 2 \% \text { depending on } \\
\text { altitude (vs. SCIA- } \\
\text { FM) }\end{array}$ \\
\hline OSIRIS & SCIA-FM & $4 \%$ & $\begin{array}{l}\text { Insignificant } \\
\text { differences (vs. } \\
\text { SCIA-FM) }\end{array}$ \\
\hline SAGE III & SCIA-FM & $\begin{array}{l}\max 1 \% \\
\text { (mesosph.) } \\
1 \% \text { (stratosphere) }\end{array}$ & $\begin{array}{l}+2 \text { to } 3 \% \\
\text { (stratosphere) }\end{array}$ \\
\hline SAGE II & $\begin{array}{l}\text { SAC } \\
\text { SCIA-FM } \\
\text { (V7) }\end{array}$ & $-1 \%$ (vs. SAC) & +2 to $3 \%$ \\
\hline
\end{tabular}

The comparisons with the recent SER cross-sections are included in the last column of Table 1. The total ozone retrievals with SER and BDM agree well, differences being of the order of $1-2 \%$ in most cases, and SER resulting higher ozone amounts. The differences with ozone profile retrievals using nadir instruments are larger (10-20\%). Systematic differences between BDM and SER cross-sections below $300 \mathrm{~nm}$ are observed as well as different temperature dependencies which affect in particular profiles from nadir looking instruments. In limb and occultation instruments the SER data lead to altitude dependent differences of few percent compared to presently used SCIA-FM cross-sections.

The spectral residual analysis of the various satellite instruments shows generally that the BDM cross-sections result in a better agreement between the measurement and modelled signal. This is a clear evidence of the better quality of BDM cross-sections over BP. In addition, based on the analysis of several instruments and algorithms the wavelength calibration and temperature characterization of BDM seem to be better than BP. Some of the algorithms also compute other indicators that can be used to quantify the goodness of the retrieval. Such parameters have been effective temperature and reflectance cost function, and they have also indicated that BDM cross-sections result in more reliable retrievals than BP cross-sections. The retrieval indicators are summarized in Table 2 below. The retrieval indicators, effective temperatures and residuals are similar for BDM and SER cross-sections suggesting equally good wavelength calibration and accuracy.

\subsection{Conclusions}

Based on the analysis of several algorithms and instruments using the Huggins band it is clear that the BDM cross-sections are better suited for ozone retrievals than the BP cross-sections. This is due to good quality of the BDM data (wavelength calibration, accuracy, lower signal-to-noise ratios) and better agreement of fit residuals, better agreement of effective temperature fits compared to BP. The difference in total ozone columns will be on the order of a few percent depending on the instrument and wavelength region used.

However, there are limitations also in the BDM cross-sections: they do not cover the temperature range below $218 \mathrm{~K}$. In addition, the $273 \mathrm{~K}$ cross-sections seem to contain systematic biases compared to other temperatures [56] and does not contain wavelengths below $300 \mathrm{~nm}$. An important requirement is that the spectral resolution of the absorption cross-section is sufficiently high $(\sim 0.01 \mathrm{~nm})$ and covers a wide wavelength range. In addition, the temperature coverage of the cross-sections is important for limb and occultation instruments that retrieve ozone profiles from troposphere to mesosphere as well as for all instruments measuring over cold polar vortices. In order to fulfil these needs, cross-sections with wider temperature and wavelength ranges are needed.

Recently new laboratory measurements have been made at the University of Bremen (Serdyuchenko et al., 2013, Gorshelev et al., 2013). These data have high spectral resolution, large wavelength $(213-1100 \mathrm{~nm})$ and temperature $(193-293 \mathrm{~K})$ coverage so that the data are potentially suitable for also limb and occultation retrievals. Nadir profiling retrievals use wider wavelength region and therefore consistency of the cross-sections in the fitting window is important. The systematic differences between BDM and SER cross-section data at low wavelengths below $300 \mathrm{~nm}$ suggest that more work is needed to judge which data are better. It is also suggested to work more to analyse the differences in the temperature dependence of the SER and BDM cross-sections. The differences between SER, SCIA-FM and SCIA-FM4 seem to be systematic at longer wavelengths (Chappuis 
Table 2

Retrieval performance summary of the various instruments and algorithms.

\begin{tabular}{|c|c|c|c|}
\hline Instrument/algorithm & Residuals & $\begin{array}{l}\text { Wavelength } \\
\text { calibration }\end{array}$ & Other tests and validation \\
\hline \multicolumn{4}{|l|}{ Total ozone columns } \\
\hline TOMS & $\begin{array}{l}\text { BDM better } \\
\text { than BP }\end{array}$ & & $\begin{array}{l}\text { BDM better temperature } \\
\text { dependence }\end{array}$ \\
\hline OMI DOAS & $\begin{array}{l}\text { BDM } \\
\text { marginally } \\
\text { worse than BP }\end{array}$ & & $\begin{array}{l}\text { BDM better effective } \\
\text { temp }\end{array}$ \\
\hline GODFIT & $\begin{array}{l}\text { GOME: } \\
\text { BDM best } \\
\text { BP worst } \\
\text { SCIA/ } \\
\text { GOME-2: } \\
\text { BP worst } \\
\text { GOME-FM \& } \\
\text { BDP } \\
\text { equal }\end{array}$ & $\begin{array}{l}\text { BDM more } \\
\text { accurate than } \\
\text { BP/GOME- } \\
\text { FM }\end{array}$ & $\begin{array}{l}\text { Effective temperature } \\
\text { using GOME: BDM } \\
\text { agree well with } \\
\text { ECMWF, BP and } \\
\text { GOME-FM result in } \\
\text { lower values }\end{array}$ \\
\hline WFDOAS & $\begin{array}{l}\text { BP worse than } \\
\text { BDM and } \\
\text { satellite FM } \\
\text { BDM slightly } \\
\text { better } \\
\text { than satellite } \\
\text { FM }\end{array}$ & $\begin{array}{l}\text { BDP more } \\
\text { accurate than } \\
\text { GOME-FM } \\
\text { and SCIA-FM }\end{array}$ & $\begin{array}{l}\text { Effective ozone } \\
\text { temperature can vary by } \\
\text { up to } 15 \mathrm{~K} \text { depending on } \\
\text { cross-section choice }\end{array}$ \\
\hline \multicolumn{4}{|l|}{ Nadir profiles } \\
\hline SBUV profile & & & $\begin{array}{l}\text { BDM: no solar zenith } \\
\text { angle dependence in } \\
\text { comparison to } \\
\text { Brewers/Dobsons. } \\
\text { BP: clear dependence }\end{array}$ \\
\hline OMI Profile & $\begin{array}{l}\text { BDM better } \\
\text { than BP } \\
\text { SER and } \\
\text { BDM similar }\end{array}$ & & $\begin{array}{l}\text { Reflectance cost } \\
\text { functions indicate that } \\
\text { BDM better than BP } \\
\text { SER vs. BDM: } \\
\text { Indication of } \\
\text { temperature dependent } \\
\text { differences. }\end{array}$ \\
\hline $\begin{array}{l}\text { Harvard algorithm } \\
\text { GOME profile }\end{array}$ & $\begin{array}{l}\text { BDM better } \\
\text { than BP } \\
\text { GOME-FM } \\
\text { better than } \\
\text { BP, but worse } \\
\text { than BDM }\end{array}$ & & $\begin{array}{l}\text { Tropospheric ozone } \\
\text { columns show better } \\
\text { agreement at two sites } \\
\text { when using BDM than } \\
\text { BP }\end{array}$ \\
\hline $\begin{array}{l}\text { Harvard algorithm } \\
\text { OMI profile }\end{array}$ & $\begin{array}{l}\text { BDM and SER } \\
\text { similar. BP } \\
\text { worse }\end{array}$ & $\begin{array}{l}\text { Retrieval } \\
\text { failures } \\
\text { observed often } \\
\text { due to } \\
\text { negative } \\
\text { ozone values } \\
\text { at some layers }\end{array}$ & $\begin{array}{l}\text { Comparison with } \\
\text { soundings: BDM within } \\
10 \% \text {. BP and SER show } \\
\text { altitude dependent } \\
\text { biases of } \pm 20-70 \% \\
\text { below } 20 \mathrm{~km}\end{array}$ \\
\hline
\end{tabular}

and Wulf bands) and further work is needed to reduce this uncertainty.

During the ACSO work it became clear that there is a strong need for clarifying situation of various retrievals/instruments and the cross-sections that are used for retrieving ozone. There are several versions of the same cross-section data, various corrections are applied to them in the retrieval and it is not straightforward to track back what is the origin of these modifications. It is important that the cross-sections are easily available and they are clearly described (resolution, slit function) and their modifications, if needed, are clearly indicated and traceable. In addition, instructions how to use them and, in particular, their temperature dependence is needed. The various cross-sections used in this study can be downloaded from the ACSO website (http://igaco-o3.fmi.fi/ACSO/).

Some satellite ozone data processing already base their retrievals on the NCEP (or other reanalysis) temperature datasets. It is not clear how daily temperature corrections might affect the high resolution profiles. This is also done for the conversion between pressure and altitude grids (including lidar processing). There is a need to investi- gate if the use of temperature for cross-section correction and pressure-to-altitude conversion combines the two effects when long-term data are analysed on the non-native grid.

In the last ACSO workshop in 2013, the importance of careful error characterization of the laboratory measurements was also emphasized. This includes both descriptions of random errors and systematic errors. Novel retrieval algorithms (in particular used for satellite retrievals) are capable of including this information in the retrievals. Proper characterization of the uncertainty of the cross-sections may lead to more optimal retrieval results, thus improving ozone estimates. Moreover, propagating the uncertainty in the cross-sections through the retrieval algorithm gives important information for the total error budget of the retrieved ozone values which is crucial when estimating e.g. significance of observed trends in ozone data.

The increasing interest to improve the retrieval of tropospheric ozone by performing jointly retrieval of UV and IR instruments (e.g. $[29,49,53])$ emphasizes the need to have consistent spectroscopy data for large wavelength region. In future, this requirement should also be considered.

\section{Uncited references}

$$
[52,54,57,71,74]
$$

\section{References}

[1] D. Daumont, J. Brion, J. Charbonnier, J. Malicet, Ozone UV spectroscopy I: absorption cross sections at room temperature, J. Atmos. Chem. 15 (1992) $145-155$.

[2] J. Brion, A. Chakir, D. Daumont, J. Malicet, C. Parisse, High resolution laboratory absorption cross section of $\mathrm{O}_{3}$ : temperature effect, Chem. Phys. Lett. 213 (1993) 610-612.

[3] J. Malicet, D. Daumont, J. Charbonnier, C. Parisse, A. Chakir, J. Brion, Ozone UV spectroscopy II: absorption cross sections and temperature dependence, J. Atmos. Chem. 21 (1995) 263-273.

[4] J. Brion, A. Chakir, J. Charbonnier, D. Daumont, C. Parisse, J. Malicet, Absorption spectra measurements for the ozone molecule in the $350-830 \mathrm{~nm}$ region, J. Atmos. Chem. 30 (1998) 291-299.

[5] A.M. Bass, R.J. Paur, The ultraviolet cross sections of ozone: I. The measurements, in Atmospheric Ozone, in: C.S. Zerefos, A. Ghazi (Eds.), Atmospheric Ozone - Proceedings of the Quadrennial Ozone Symposium 1984, 1985pp. 606-610. Dordrecht Reidel, Norwell, MA.

[6] R.J. Paur, A.M. Bass, The ultraviolet cross-sections of ozone: II. Results and temperature dependence, in Atmospheric Ozone, in: C.S. Zerefos, A. Ghazi (Eds.), Proceedings of the Quadrennial Ozone Symposium 1984, 1985pp. 611-615. Dordrecht Reidel, Norwell, MA.

[7] V. Gorshelev, A. Serdyuchenko, M. Weber, W. Chehade, J.P. Burrows, 2014: High spectral resolution ozone absorption cross-sections - Part 1: measurements, data analysis and comparison with previous measurements around 293 K, Atmos. Measure. Tech. 7 (2014) 609-624, http://dx.doi.org/10.5194/ amt-7-609-2014.

[8] A. Serdyuchenko, V. Gorshelev, M. Weber, W. Chehade, J.P. Burrows, High spectral resolution ozone absorption cross-sections - Part 2: temperature dependence, Atmos. Measure. Tech. 7 (2014) 625-636, http://dx.doi.org/10.5194/ amt-7-625-2014.

[9] B. Hassler, I. Petropavlovskikh, J. Staehelin, T. August, P.K. Bhartia, C. Clerbaux, D. Degenstein, M. De Mazière, B.M. Dinelli, A. Dudhia, G. Dufour, S.M. Frith, L. Froidevaux, S. Godin-Beekmann, J. Granville, N.R.P. Harris, K. Hoppel, D. Hubert, Y. Kasai, M.J. Kurylo, E. Kyrölä, J.-C. Lambert, P.F. Levelt, C.T. McElroy, R.D. McPeters, R. Munro, H. Nakajima, A. Parrish, P. Raspollini, E.E. Remsberg, K.H. Rosenlof, A. Rozanov, T. Sano, Y. Sasano, M. Shiotani, H.G.J. Smit, G. Stiller, J. Tamminen, D.W. Tarasick, J. Urban, R.J. Van der A, J.P. Veefkind, C. Vigouroux, T. von Clarmann, C. von Savigny, K.A. Walker, M. Weber, J. Wild, J.M. Zawodny, Past changes in the vertical distribution of ozone - Part 1: Measurement techniques, uncertainties and availability, Atmos. Measure. Tech. 7 (2014) (2014) 1395-1427, http://dx.doi.org/10. 5194/amt-7-1395-2014.

[10] J. Orphal, A critical review of the absorption cross sections of $\mathrm{O}_{3}$ and $\mathrm{NO}_{2}$ in the 240-790 nm region. Part I: Ozone, ESA Technical Note MO-TN-ESA-GO-0302, 2002. Available at: < http://igaco-o3.fmi.fi/ACSO/files/ 2002-ESA-O3.pdf>. 
[11] J. Orphal, A critical review of the absorption cross sections of O3 and NO2 in the 240-790 nm region, J. Photochem. Photobiol. A 157 (2003) 185-209.

[12] J. Viallon, P. Moussay, J.E. Norris, F.R. Guenther, R.I. Wielgosz, A study of systematic biases and measurement uncertainties in ozone mole fraction measurements with the NIST Standard Reference Photometer, Metrologia 43 (5) (2006) 441-450.

[13] M. Petersen, J. Viallon, P. Moussay, R.I. Wielgosz, Relative measurements of ozone absorption cross-sections at three wavelengths in the Hartley band using a well-defined UV laser beam, J. Geophys. Res. D 117 (2012) D05301, http://dx. doi.org/10.1029/2011JD016374.

[14] J. Viallon, S. Lee, P. Moussay, K. Tworek, M. Petersen, R.I. Wielgosz, Accurate laser measurements of ozone absorption cross-sections in the Hartley band, Atmos. Measure. Tech. 8 (2015) 1245-1257, http://dx.doi.org/10.5194/ amt-8-1245-2015.

[15] M. Guinet, M.D. Mondelain, C. Janssen, C. Camy-Peyret, Laser spectroscopic study of ozone in the $100 \leftarrow 000$ band for the SWIFT instrument, J. Quant. Spectrosc. Radiat. Transfer 111 (2010) 961-972, http://dx.doi.org/10.1016/j.jqsrt. 2010.01.011.

[16] C. Janssen, D. Simone, M. Guinet, Preparation and accurate measurement of pure ozone, Rev. Sci. Instrum. 82 (2011) 034102, http://dx.doi.org/10.1063/1. 3557512 .

[17] M. Guinet, D. Mondelain, C. Camy-Peyret, C. Janssen, Absolute ozone absorption cross section at the $253.55 \mathrm{~nm}$ mercury line position, in preparation.

[18] J.P. Burrows, A. Richter, A. Dehn, B. Deters, S. Himmelmann, S. Voigt, J. Orphal, Atmospheric remote sensing reference data from GOME: 2. Temperature dependent absorption cross sections of $\mathrm{O} 3$ in the 231-794 nm range, J. Quant. Spectrosc. Radiat. Transfer 61 (1996) 509-517.

[19] S. Voigt, J. Orphal, K. Bogumil, J.P. Burrows, The temperature dependence (203-293 K) of the absorption cross-sections of O3 in the $230-850 \mathrm{~nm}$ region measured by Fourier-transform spectroscopy, J. Photochem. Photobiol. A 143 (2001) 1-9.

[20] K. Bogumil, J. Orphal, T. Homann, S. Voigt, P. Spietz, O.C. Fleischmann, A. Vogel, M. Hartmann, H. Bovensmann, J. Frerick, J.P. Burrows, Measurements of molecular absorption spectra with the SCIAMACHY pre-flight model: instrument characterization and reference data for atmospheric remote sensing in the 230-2380 nm region, J. Photochem. Photobiol. A (2003) 157-167.

[21] J. Orphal, K.V. Chance, Ultraviolet-visible absorption cross-sections in HITRAN, J. Quant. Spectrosc. Radiat. Transfer 82 (2003) 491-504.

[22] J.-M. Flaud, G. Wagner, M. Birk, C. Camy-Peyret, C. Claveau, M.-R. De Backer-Barilly, A. Barbe, C. Piccolo, The ozone absorption around $10 \mu \mathrm{m}, \mathrm{J}$. Geophys. Res. 108 (2003) 4269, http://dx.doi.org/10.1029/2002JD002755.

[23] C.P. Rinsland, J.-M. Flaud, A. Perrin, M. Birk, G. Wagner, A. Goldman, A. Barbe, M.-R. De Backer-Barilly, S.N. Mikhailenko, Vl.G. Tyuterev, M.A.H. Smith, V. Malathy Devi, D.C. Benner, F. Schreier, K.V. Chance, J. Orphal, T.M. Stephen, Spectroscopic parameters for ozone and its isotopes: recent measurements, outstanding issues, and prospects for improvements to HITRAN, J. Quant. Spectrosc. Radiat. Transfer 82 (2003) 207-218.

[24] B. Picquet-Varrault, J. Orphal, J.-F. Doussin, P. Carlier, J.-M. Flaud, Laboratory intercomparison of the ozone absorption coefficients in the mid-infrared (10 $\mu \mathrm{m})$ and ultraviolet (300-350 nm) spectral regions, J. Phys. Chem. A 109 (2005) 1008-1014.

[25] M. Schneider, A. Redondas, F. Hase, C. Guirado, T. Blumenstock, E. Cuevas, Comparison of ground-based Brewer and FTIR total column $\mathrm{O}_{3}$ monitoring techniques, Atmos. Chem. Phys. 8 (2008) 5535-5550, http://dx.doi.org/10.5194/ acp-8-5535-2008

[26] A. Gratien, B. Picquet-Varrault, J. Orphal, J.-F. Doussin, J.-M. Flaud, New laboratory intercomparison of the ozone absorption coefficients in the mid-infrared $(10 \mu \mathrm{m})$ and ultraviolet (300-350 nm) spectral regions, J. Phys. Chem. A 114 (2010) 10045-10048.

[27] C. Viatte, M. Schneider, A. Redondas, F. Hase, M. Eremenko, P. Chelin, J.-M. Flaud, T. Blumenstock, J. Orphal, Validation of IASI $\mathrm{O}_{3}$ total columns at Izaña by comparison with data from ground-based FTIR, Brewer, and from the OMI and GOME-2 satellite instruments, Atmos. Measure. Tech. 4 (2011) 535-546.

[28] C. Viatte, B. Gaubert, M. Eremenko, F. Hase, M. Schneider, T. Blumenstock, P. Chelin, J.-M. Flaud, J. Orphal, Tropospheric and total ozone columns over Paris (France) measured using medium-resolution ground-based solar-absorption Fourier-transform infrared spectroscopy, Atmos. Measure. Tech. 4 (2011) 2323-2331.

[29] J. Cuesta, M. Eremenko, X. Liu, G. Dufour, Z. Cai, M. Höpfner, T. von Clarmann, P. Sellito, G. Foret, B. Gaubert, J. Orphal, K.V. Chance, R. Spurr, J.-M. Flaud, Lowermost tropospheric ozone observation by multispectral synergism of IASI thermal IR and GOME-2 UV satellite measurements", Atmos. Chem. Phys. 13 (2013) 9675-9693.

[30] J.B. Burkholder, R.K. Talukdar, Temperature-dependence of the ozone absorption spectrum over the wavelength range 410 to $760 \mathrm{~nm}$, Geophys. Res. Lett. 21 (1984) 581-584.

[31] J.B. Burkholder, unpublished.
[32] B. Gür, Temperature Dependent Absorption Cross Sections of $\mathrm{O}_{3}$ and $\mathrm{NO}_{2}$ in the 240-790 nm Range Determined by using the GOME 2 Satellite Spectrometers for Use in Remote Sensing Applications, Ph.D. Thesis Faculty of Physics, University of Bremen, 2006. <http://elib.suub.unibremen.de/diss/docs/ 00010345.pdf>.

[33] W. Chehade, B. Gür, P. Spietz, V. Gorshelev, A. Serdyuchenko, J.P. Burrows, M. Weber, Temperature dependent ozone absorption cross section spectra measured with the GOME-2 FM3 spectrometer and first application in satellite retrievals, Atmos. Measure. Tech. 6 (2013) 1623-1632, http://dx.doi.org/10.5194/ amt-6-1623-2013.

[34] W. Chehade, V. Gorshelev, A. Serdyuchenko, J.P. Burrows, M. Weber, Revised temperature-dependent ozone absorption cross-section spectra (Bogumil et al.) measured with the SCIAMACHY satellite spectrometer, Atmos. Measure. Tech. 6 (2013) 3055-3065, http://dx.doi.org/10.5194/amt-6-3055-2013.

[35] X. Thomas, P. Von Der Heyden, M.-R. De Backer-Barilly, A. Barbe, Infrared absolute intensities of ozone in the 10 and $5 \mu \mathrm{m}$ spectral range: new investigations, J. Quant. Spectrosc. Radiat. Transfer 111 (2010) 1080-1088.

[36] A.G. Hearn, The absorption of ozone in the ultra-violet and visible regions of the spectrum, Proc. Phys. Soc. 78 (1961) 932-940, http://dx.doi.org/10.1088/ 0370-1328/78/5/340

[37] J.L. Axson, R.A. Washenfelder, T.F. Kahan, C.J. Young, V. Vaida, S.S. Brown, Absolute ozone absorption cross section in the Huggins Chappuis minimum (350-470 nm) at 296K, Atmos. Chem. Phys. 11 (2011) 11581-11590.

[38] J. Chen, D.S. Venables, A broadband optical cavity spectrometer for measuring weak near-ultraviolet absorption spectra of gases, Atmos. Measure. Tech. 4 (2011) 425-436.

[39] M.A.H. Smith, V.M. Devi, D.C. Benner, The quest for ozone intensities in the 9-11 $\mu \mathrm{m}$ region: a retrospective, J. Quant. Spectrosc. Radiat. Transfer 113 (2012) 825-828.

[40] R.E. Basher, Ozone absorption coefficients' role in Dobson instrument ozone measurement accuracy, Geophys. Res. Lett. 9 (1982) 1235-1238.

[41] P.K. Bhartia, C.G. Wellemeyer, S.L. Taylor, N. Nath, A. Gopolan, Solar backscatter ultraviolet (SBUV) version 8 profile algorithm, In: Proceedings of the Quadrennial Ozone Symposium, Kos, Greece, 1-8 June 2004, 2004pp. 295-296.

[42] A. Bracher, L.N. Lamsal, M. Weber, K. Bramstedt, M. Coldewey-Egbers, J.P. Burrows, Global satellite validation of SCIAMACHY $\mathrm{O}_{3}$ columns with GOME WFDOAS, Atmos. Chem. Phys. 5 (2005) 2357-2368.

[43] J.P. Burrows, M. Weber, M. Buchwitz, V.V. Rozanov, A. Ladstädter Weissenmayer, A. Richter, R. de Beek, R. Hoogen, K. Bramstedt, K.U. Eichmann, M. Eisinger, D. Perner, The global ozone monitoring experiment (GOME): mission concept and first scientific results, J. Atmos. Sci. 56 (151) (1999) 175.

[44] CIRA 1986, 1990: Part II middle atmosphere models, in: D. Rees, J.J. Barnett, K. Labitzke (Eds.), Advances in Space Research (COSPAR), 10(12).

[45] M. Coldewey-Egbers, M. Weber, L.N. Lamsal, R. de Beek, M. Buchwitz, J.P. Burrows, Total ozone retrieval from GOME UV spectral data using the weighting function DOAS approach, Atmos. Chem. Phys. 5 (2005) 5015-5025.

[46] D.A. Degenstein, A.E. Bourassa, C.Z. Roth, F.J. Llewellyn, Limb scatter ozone retrieval from 10 to $60 \mathrm{~km}$ using a multiplicative algebraic reconstruction technique, Atmos. Chem. Phys. 9 (2009) 6521-6529, http://dx.doi.org/10.5194/ acp-9-6521-2009.

[47] R. Evans, G. Mcconville, S. Oltmans, I. Petropavlovskikh, D. Quincy, Measurement of internal stray light within Dobson ozone spectrophotometers, Int. J. Remote Sens. 30 (2009) 4247-4258, http://dx.doi.org/10.1080/ 01431160902825057 .

[48] K. Fragkos, A.F. Bais, D. Balis, C. Meleti, M.E. Koukouli, The effect of three different absorption cross-sections and their temperature dependence on total ozone measured by a mid-latitude Brewer spectrophotometer, Atmos. Ocean 53 (1) (2015) 19-28.

[49] D. Fu, J.R. Worden, X. Liu, S.S. Kulawik, K.W. Bowman, V. Natraj, Characterization of ozone profiles derived from Aura TES and OMI radiances, Atmos. Chem. Phys. 13 (2013) 3445-3462.

[50] GCOS-154, Systematic Observation Requirements for Satellite based Data Products for Climate, 2011 Update, Supplemental Details to the Satellite-based Component of the "Implementation Plan for the Global Observing System for Climate in Support of the UNFCCC", 2011, <http://www.wmo.int/pages/prog/ gcos/documents/SatelliteSupplement2011Update.pdf>

[51] G. Kiesewetter, B.-M. Sinnhuber, M. Weber, J.P. Burrows, Attribution of stratospheric ozone trends to chemistry and transport: a modelling study, Atmos. Chem. Phys. 10 (2010) 12073-12089, http://dx.doi.org/10.5194/ acp-10-12073-2010.

[52] H.L. Kurucz, The solar spectrum: atlases and line identifications, workshop on laboratory and astronomical high resolution spectra. astronomical society of the pacific conference series, in: A.J. Sauval, R. Blomme, N. Grevesse (Eds.), Proceedings of ASP Conference No. 81 Held in Brussels, Belgium 29 August-2 September 1994, Astronomical Society of the Pacific (ASP), San Francisco, 1995, pp. 17-31.

[53] J. Landgraf, O.P. Hasekamp, Retrieval of tropospheric ozone: the synergistic use of thermal infrared emission and ultraviolet reflectivity measurements from 
space, J. Geophys. Res. 112 (2007) D08310, http://dx.doi.org/10.1029/ 2006JD008097.

[54] C. Lerot, M. Roozendael, J. van Geffen, J. van Gent, C. Fayt, R. Spurr, G. Lichtenberg, A.. von Bargen, Six years of total ozone column measurements from SCIAMACHY nadir observations, Atmos. Measure. Tech. 2 (2009) 87-98.

[55] C. Lerot, M. Van Roozendael, R. Spurr, D. Loyola, M. Coldewey-Egbers, S. Kochenova, J. van Gent, M. Koukouli, D. Balis, J.-C. Lambert, J. Granville, C. Zehner, Homogenized total ozone data records from the European sensors GOME/ERS-2, SCIAMACHY/Envisat, and GOME-2/MetOp-A, J. Geophys. Res.: Atmos. 119 (2014) 1639-1662, http://dx.doi.org/10.1002/2013JD020831.

[56] X. Liu, K. Chance, C.E. Sioris, T.P. Kurosu, Impact of using different ozone cross sections on ozone profile retrievals from Global Ozone Monitoring Experiment (GOME) ultraviolet measurements, Atmos. Chem. Phys. 7 (2007) 3571-3578.

[57] X. Liu, P.K. Bhartia, K. Chance, R.J.D. Spurr, T.P. Kurosu, Ozone profile retrievals from the ozone monitoring instrument, Atmos. Chem. Phys. 10 (2010) 2521-2537.

[58] C. Liu, X. Liu, K. Chance, The impact of using different ozone cross sections on ozone profile retrievals from OMI UV measurements, J. Quant. Spectrosc. Radiat. Transfer (2013) http://dx.doi.org/10.1016/j.jqsrt.2013.06.006.

[59] K. Miyagawa, T. Sasaki, H. Nakane, I. Petropavlovskikh, R.D. Evans, Reevaluation of long-term Umkehr Data and Ozone profiles, J. Geophys. Res. 15 (4043-15) (2009) 4053, http://dx.doi.org/10.1029/2008JD010658.

[60] R.D. McPeters, P.K. Bhartia, A.J. Krueger, J.R. Herman, C.G. Wellemeyer, C.J. Seftor, G. Jaross, O. Torres, L. Moy, G. Labow, W. Byerly, S.L. Taylor, T. Swissler, R.P. Cebula, Earth Probe Total Ozone Mapping Spectrometer (TOMS) Data Products User's Guide, NASA/TP-1998-206895, 1998.

[61] R.D. McPeters, G.J. Labow, J.A. Logan, Ozone climatological profiles for satellite retrieval algorithms, J. Geophys. Res. 112 (2007) http://dx.doi.org/10.1029/ 2005JD006823.

[62] M. Pastel, S. Godin-Beekmann, T. Leblanc, Sensitivity of LIDAR Measurements on Ozone Cross-Sections, Report, December, 2013.

[63] D. Perner, U. Platt, Detection of nitrous acid in the atmosphere by differential optical absorption, Geophys. Res. Lett. 6 (1979) 917-920.

[64] I. Petropavlovskikh, P.K. Bhartia, J. DeLuisi, New Umkehr ozone profile retrieval algorithm optimized for climatological studies, Geophys. Res. Lett. 32 (2005) L16808, http://dx.doi.org/10.1029/2005GL023323.

[65] I. Petropavlovskikh, R. Evans, G. Mcconville, S. Oltmans, D. Quincy, K. Lantz, P. Disterhoft, M. Stanek, L. Flynn, Sensitivity of Dobson and Brewer Umkehr ozone profile retrievals to ozone cross sections and stray light effects, Atmos. Measure. Tech. 4 (2011) 1841-1853.
[66] A. Redondas, R. Evans, R. Stuebi, U. Köhler, M. Weber, Evaluation of the use of five laboratory-determined ozone absorption cross sections in Brewer and Dobson retrieval algorithms, Atmos. Chem. Phys. 14 (2014) 1635-1648, http:// dx.doi.org/10.5194/acp-14-1635-2014.

[67] C.D. Rodgers, Inverse Methods for Atmospheric Sounding: Theory and Practice, World Scientific Publishing, Singapore, 2000.

[68] B. Scarnato, J. Staehelin, T. Peter, J. Gröbner, R. Stübi, Temperature and slant path effects in Dobson and Brewer total ozone measurements, J. Geophys. Res. 114 (D24) (2009) D24303.

[69] E.P. Shettle, S. Anderson, New visible and near IR ozone absorption cross-sections for MODTRAN, in: G.P. Anderson, R.H. Picard, J.H. Chetwynd (Eds.), Proceedings of the 17th Annual Review Conference on Atmospheric Transmission Models, 8-9 June 1994, PL-TR-95-2060, Phillips Laboratory, Hanscom AFB, MA, 1995, pp. 335-345.

[70] M.E. Summers, W. Sawchuck, Zonally Averaged Trace Constituent Climatology. A Combination of Observational Datasets and 1-D and 2-D Chemical-Dynamical Model Result, Naval Research Laboratory, Technical Report, NRL/ MR/7641-93-7416, Washington, DC, 1993.

[71] M. Van Roozendael, V. Soebijanta, C. Fayt, J.C. Lambert, Investigation of DOAS Issues Affecting the Accuracy of the GDP version 3.0 Total Ozone Product, see Chapter VI of $<$ http://earth.esrin.esa.it/pub/ESA_DOC/GOME/gdp3/ gdp3.htm>, 2003.

[72] M. Van Roozendael, D. Loyola, R.J. Spurr, D. Balis, J.C. Lambert, Y. Livschitz, P. Valks, T. Ruppert, P. Kenter, C. Fayt, C. Zehner, Ten years of GOME/ERS 2 total ozone data. The new GOME data processor (GDP) version 4: 1. Algorithm description, J. Geophys. Res. 111 (2006) D14311, http://dx.doi.org/10.1029/ 2005JD006375.

[73] J.P. Veefkind, J.F. de Haan, E.J. Brinksma, M. Kroon, P.F. Levelt, Total ozone from the ozone monitoring instrument (OMI) using the DOAS technique, IEEE Trans, Geosci. Remote Sens. 44 (2006) 1239-1244, http://dx.doi.org/10.1109/ TGRS.2006.871204

[74] E. Vigroux, Contribution de l'etude experimentale de l'absorption de l'ozone, Ann. Phys. 8 (1953) 709-762.

[75] M. Weber, L.N. Lamsal, M. Coldewey-Egbers, K. Bramstedt, J.P. Burrows, Pole to pole validation of GOME WFDOAS total ozone with groundbased data, Atmos. Chem. Phys. 5 (2005) 1341-1355.

[76] M. Weber, W. Steinbrecht, Stratospheric Ozone, in "State of the Climate" in 2009, Bull. Am. Meteorol. Soc. 91 (2010) S46-S48. 